\title{
Flare performance modeling and set point determination using artificial neural networks
}

\author{
Vijaya Durga Damodara ${ }^{1}$ - Arokiaraj Alphones ${ }^{1} \cdot$ Daniel H. Chen ${ }^{1} \cdot$ Helen H. Lou ${ }^{1}$ Christopher Martin ${ }^{3}$. \\ Xianchang $\mathrm{Li}^{2}$
}

Received: 13 January 2019 / Accepted: 5 August 2019 / Published online: 13 August 2019

(c) The Author(s) 2019

\begin{abstract}
Current EPA regulations mandate a minimum combustion zone heating value of $270 \mathrm{BTU} / \mathrm{scf}$ and a net heating value dilution parameter of $\mathrm{NHV}_{\mathrm{dil}} \geq 22 \mathrm{BTU} / \mathrm{ft}^{2}$ for all steam/air/non-assisted flares while maintaining a high combustion efficiency (CE). To achieve the target performance along with satisfying the EPA regulations, it is necessary to understand the influence of various operating parameters. Studying the effect of operating parameters through experiments is both expensive and time consuming. It is more cost effective to use validated models to guide flare operations. In this study, controlled flare test data conducted from 1983 to 2014 with a wide range of exit velocities, heating values, and fuel compositions have been modeled. The purpose of this study is to develop models that can be robustly used in the industry to achieve the desired CE without visible emissions (smoke). Steam-/air-assist rates, exit velocity, and the vent gas composition, which can be either controlled or measured in flare operations, are used as independent variables in the models. Neural network (NN) models were developed for the air-assisted, steam-assisted, and non-assisted flares using various types of fuels like propylene, propane, natural gas, methane, and ethylene. The flare performance models such as CE and opacity were developed using neural network toolbox in MATLAB. NN models for steam and air-assisted flare tests are in good agreement with experimental data and have been demonstrated by the average correlation coefficient of 0.95 and 0.97 for air-assisted and steam-assisted flare data, respectively. The very low mean absolute errors of $1.1 \%$ and $1.4 \%$ for air-assisted and steam-assisted flare data, respectively, also indicate the robustness of the NN models. 2-D and 3-D contour plots are presented to show the effect of key operating parameters. The set points (amount of steam/air/make-up fuel required) at the Incipient Smoke Point (ISP) and for Smokeless Flaring (SLF) have been developed based on the neural network models performed in this study. Desirable operating inputs can be set for the ISP and for SLF (Opacity $\leq$ Opacity ${ }_{\text {ISP }}$ ) subject to heating value constraints $\left(\mathrm{NHV}_{\mathrm{dil}} \geq 22 \mathrm{BTU} / \mathrm{ft}^{2} \& \mathrm{NHV}_{\mathrm{CZ}} \geq 270\right.$ BTU/scf) with a high CE ( $\geq 96.5 \%)$ for the 1984 EPA and 2010 TCEQ flare study test cases.
\end{abstract}

Keywords Combustion efficiency $\cdot$ Opacity $\cdot$ Neural network $\cdot$ Incipient smoke point

\section{List of symbols}

$\begin{array}{ll}\text { A } & \text { Air-assist flow (lb/MMBTU) } \\ \text { BTU } & \text { British thermal unit } \\ \text { CE } & \text { Combustion efficiency, \% }\end{array}$

Vijaya Durga Damodara

vijaya_damodara@yahoo.com

Arokiaraj Alphones

arokia2002@gmail.com

Daniel H. Chen

dhchen@lamar.edu

Helen H. Lou

hhlou@lamar.edu

Christopher Martin

martincb@lamar.edu

$\begin{array}{ll}\text { CHR } & \text { Carbon to hydrogen molar ratio } \\ \text { CN } & \text { Carbon number } \\ \text { D } & \text { Flare tip diameter (ft.) } \\ \text { EPA } & \text { Environmental protection agency }\end{array}$

Xianchang Li

xli2@lamar.edu

1 Dan F. Smith Department of Chemical Engineering, Lamar University, Beaumont, TX 77710, USA

2 Mechanical Engineering, Lamar University, Beaumont, TX 77710, USA

3 Department of Chemistry and Biochemistry, Lamar University, Beaumont, TX 77710, USA 


$\begin{array}{ll}\mathrm{F} & \text { Make-up fuel (BTU/scf) } \\ \text { ISP } & \text { Incipient smoke point } \\ \mathrm{lb} / \mathrm{hr} & \text { Pounds per hour } \\ \text { MAE } & \text { Mean absolute error } \\ \text { MMBTU } & \text { Millions of BTU } \\ \text { NHV } & \text { Net heating value (BTU/scf) } \\ \text { NHV }_{\mathrm{CZ}} & \text { Combustion zone heating value }(\mathrm{BTU} / \mathrm{scf}) \\ \mathrm{NHV}_{\text {dil }} & \text { Net heating value dilution parameter }\left(\mathrm{BTU} / \mathrm{ft}^{2}\right) \\ \mathrm{NN} & \text { Neural network } \\ \mathrm{r} & \text { Correlation coefficient } \\ \mathrm{R} & \text { U/V ratio } \\ \mathrm{S} & \text { Steam-assist flow (lb/MMBTU) } \\ \text { scf } & \text { Standard cubic feet } \\ \mathrm{SLF} & \text { Smokeless flaring } \\ \text { TCEQ } & \text { Texas commission on environmental quality } \\ \text { TNG } & \text { Tulsa natural gas } \\ \mathrm{U} & \text { Crosswind velocity }(\mathrm{ft} / \mathrm{s}) \\ \mathrm{V} & \text { Exit velocity }(\mathrm{ft} / \mathrm{s}) \\ \text { VE } & \text { Variance explained } \\ \end{array}$

\section{Introduction and literature survey}

When utilization or conservation of waste gas streams is not practicable, flaring is environmentally preferable to venting since this tends to reduce Green House Gases, Volatile Organic Compounds (VOC), and Hazardous Air Pollutants (HAPs) emissions. This seemingly simple process is rather complicated since flare performance is affected by many parameters, most of which never remain constant. The most common among these variables are the fuel to air-/steamassist ratios, the heating value of the fuel, jet velocity, and meteorological conditions. Flare gas emissions are primarily estimated based on a few assumptions about the volume of gas sent to the flare stack, its chemical composition, and the presumed combustion efficiency [1,2]. Although the USEPA states that destruction efficiency for normal industrial flaring practices is $98 \%$, these assumptions are under scrutiny by agencies these days.

The U.S. Environmental Protection Agency (EPA) estimates there are about 500 flares in over 100 U.S. refineries but many more in chemical plants and drilling sites. The number of permits for flaring in Texas rose from just over a hundred in 2008-2000 in 2012 [3-6]. The world bank estimates that about 140 billion cubic meters of gas was flared in 2016-2017 globally, which is about 7 billion cubic meters less than 2016 [4]. Improper operation of an industrial flare can result in hundreds of tons of excess air toxics emissions. Air emissions may contribute to increased ground-level ozone and climate change [7-13]. Large sources of methane emissions from natural gas production were observed from shale gas wells. Fugitive methane emissions in the production process can counter the advantages over coal with respect to climate change $[9,10]$. Visible Infrared Imaging Radiometer Suite data may provide site-specific tracking of natural gas flaring to evaluate efforts to reduce and eliminate routine flaring $[14,15]$. Proper flare design considerations are required to safely dispose of the waste gases, some of which include the type of flare (gas/liquid), composition of fuel, temperature, flowrate, gas pressure and hydraulics [5, 16-19]. In a research by Ismail et al., percentage of stoichiometric air, natural gas type, carbon mass content, impurities and combustion efficiency of the flare system impact the quantity and pattern of chemical species in combustion zone during flaring [6]. Incomplete combustion from flares contributes to black carbon (soot) emissions. Plume samples from 37 unique flares in the Bakken region of North Dakota in May 2014 showed no obvious relationship between methane and $\mathrm{BC}$ emission factors. It was observed that efficiency distribution was skewed, exhibiting log-normal behavior [13]. There is a need to consider skewed distributions when assessing flare impacts globally.

In the Fact Sheet for the Proposed Petroleum Refinery Sector Risk and Technology Review and New Source Performance Standards, the EPA states that the proposed new standards for flares will decrease VOC (Volatile Organic Compound) emissions from flares by 33,000 tons per year [20-26]. It is also estimated that the total VOC emission reductions for all affected sources in this proposed rule are 52,000 tons per year. The flare portion accounts for $63 \%$ of the total reductions. There are more flares in chemical and petrochemical sectors than in other sectors. Flaring activities (61\%) are among the top three Highly Reactive Volatile Organic Compounds (HRVOC) emission sources in Texas. 40CFR60.18 requires smokeless flaring, which motivates flare operators to over-steam or over-air at the expense of combustion efficiency (CE) and destruction efficiency (DE) [16-18]. Due to the complex interactions between vent species, exit velocity, vent gas heating value, and assisted steam/ air, it is not trivial to determine the right flare set points to comply with the EPA regulations and to minimize fuel costs at the same time [16-19, 27-29]. Consequently, inferential models that can predict flare operation set points for environmental compliance as well as energy savings are indispensible. This study focuses on developing robust neural network inferential flare models that can (1) express CE and opacity as a function of operating variables, (2) identify the steam and fuel set points of the incipient smoke point (ISP) and smokeless flaring (SLF) for $\mathrm{NHV}_{\mathrm{CZ}} \geq 270 \mathrm{Btu} / \mathrm{scf}$ and $\mathrm{NHV}_{\text {dil }} \geq 22 \mathrm{Btu} / \mathrm{ft}^{2}$ and at the lowest fuel assist, The inferential models can be used to predict the steam/air and fuel set points in a feed-forward manner.

Neural network (NN) models based on experimental data were developed. Model input variables such as steam (S) or air (A), vent gas net heating value $\left(\mathrm{NHV}_{\mathrm{VG}}\right)$, make-up fuel $(\mathrm{F})$, vent gas exit velocity $(\mathrm{V})$, carbon number $(\mathrm{CN})$, carbon 
to hydrogen atomic ratio (CHR), and tip diameter (D) were used. We also developed models that require only calorimeter data rather than a GC (gas chromatography) data. The role of this paper is a unique contribution to flare performance modeling based on readily available flare operation parameters. The flare field tests are extremely costly due to the large amount of fuel gases involved and the dedicated instruments (GC, FTIR, and other imaging devices) required to measure emissions and combustion efficiency [30-38]. While flare simulations could be done using CFD models, the endeavors are extremely time-consuming and have convergence difficulties/accuracy issues at times [39-41]. Neural networks have been shown to be a powerful modeling tool for a wide variety of applications, most of which involve finding trends in large quantities of data. Artificial neural networks can save time and money using data-driven techniques to predict the efficiency of flares or required steam/ air assists to achieve smokeless flaring, rather than performing many experiments to gain the same information. Neural network toolbox in MATLAB has been used for model development. Air-assisted and steam-assisted flare data are used in the neural network models. A two-layer feed-forward network with sigmoid hidden neurons and linear output neurons was used to fit the flare data using one hidden layer. The network was trained with the Levenberg-Marquardt backpropagation algorithm [42-44].

Artificial neural networks have gained much attention in science and engineering applications over the past decade [39-51]. Various studies involving data modeling, most significantly nonlinear type of data, have been done using neural networks. In a study conducted by Carillo et al., [52] 129 neutron spectra data were successfully trained, tested, and validated using artificial neural network in MATLAB. Wang et al. [53] successfully validated a solar flare forecasting model based on a back-propagation artificial neural network with back-propagation training, similar to the current study. Parameters influencing gas flaring have been studied using MATLAB by Kahforoshan et al. [54]. Efforts have been made in developing software applications to study the impact of atmospheric conditions on flares [55]. Another useful application to estimate the efficiency for digester gas and landfill gas flares has been proposed by Water Environment Research Foundation [56]. In another study by Tamas [57], statistical models, particularly artificial neural networks, were found to show good results in the prediction of ozone concentration. ANN modeling was used with pollutant and meteorological data for operational forecasting of atmospheric pollutants in their study. Argonne National Laboratory research proposed an innovative model to estimate the greenhouse gases from vented, flared, and fugitive emissions based on EPA regulations [58]. Hsu et al. [59] presented a novel method to identify the structure and parameters of three-layer feed-forward ANN models. The study demonstrated the potential of ANN models for simulating nonlinear hydrologic behavior of watersheds. Benardos et al. [60] proposed a methodology for determining the best network design based on the use of a genetic algorithm (GA) and quantify an ANN's performance and its intricacy. Hagan and Demuth [61] studied ANN and back-propagation algorithm for training multilayer perceptron and its application in control systems.

\section{Neural network design}

An artificial neural network (ANN) is a mathematical model that is inspired by the organization and function aspects of biological neurons. It is a powerful data modeling tool able to capture and represent complex input/output relationships. It has a highly interconnected group of artificial neurons which processes the external information through various complex computations to build a mathematical relation between the inputs and the outputs. In this study, artificial neural network models have been used to interpret and characterize the flare data obtained from various data sources.

The work scheme of neural network involves a few important steps:

- Data collection.

- Neural network skeleton creation.

- Network configuration.

- Training the network.

- Validate the create network.

- Final network usage.

- Set point determination.

\section{Data collection}

Experimental data were collected from previous flare study reports including flare efficiency study [36], evaluation of efficiency of industrial flares [38], 2010 Texas Commission of Environmental Quality (TCEQ) Flare study final report [30], Marathon Petroleum company flare study reports [31, 32], flare testing and monitoring by Providence Photonics, LLC [23, 33], and Carleton University Soot Emission Rate Measurement Results [34, 35]. The data collected from the literature include the geometry of the steam-assist and airassist flares, meteorological data like crosswind speed/direction, humidity, and temperature, flare efficiencies, and soot emission/opacity observation data. The flare tests conducted include different fuel mixtures such as propylene, propane, natural gas, methane, ethylene, and typical refinery fuel. Therefore, a parameter to represent the carbon to hydrogen molar ratio, CHR, of vent gas species and carbon number of fuel species was used. 


\section{Neural network transfer function}

Real brain neurons get signals from other neurons and decide whether to implement by taking the cumulative input into account. This 'decision' based on the 'cumulative input', is what is modeled by the 'transfer function'. Neural networks must implement complex mapping functions and so they need activation/transfer functions that are nonlinear to bring in the much-needed non-linearity. A neuron without an activation function is equivalent to a neuron with a linear activation function. In this study, the sigmoid activation function $[45,46]$ is used in the hidden layer of neurons. It is an acceptable mathematical representation of a biological neuron behavior. Hyperbolic tangent sigmoid function has a wide range of applications due to its output being zero centered, the range being in between -1 and 1 . The output shows if the neuron is firing or not. A tangent sigmoid activation function can be mathematically written as follows:

$\operatorname{Tansig}(a)=\frac{2}{1+\mathrm{e}^{-2 * a}}-1$,

where $a$ is the cumulative input. The neuron has a bias $b$, which is summed with the weighted inputs to form the net input $a$.

$a=w_{1, i} \times p_{i}+b$,

where $i$ represents one element in the input vector.

\section{Feed-forward back-propagation algorithm}

A neural network created thus needs to be configured and then trained. After the network has been configured, the weights and biases need to be tuned to optimize the network performance, also called network training. The Levenberg-Marquardt (LM) back-propagation algorithm is used to train the networks to fit the input and target variables. The Levenberg-Marquardt algorithm is widely used to solve nonlinear least squares problems. It is a curve-fitting method that combines the advantages of the gradient descent and the Gauss-Newton(GN) methods. At each iteration, the gradient descent approach minimizes the solution by choosing parameters that make the function value smaller. More specifically, the sum of the squared errors is reduced by moving toward a direction interpolated between the steepest descent direction and the direction heading the optimal point predicted by the Gauss-Newton algorithm. Feed-forward network with one hidden layer of 'tansig' neurons followed by an output layer of linear neurons was used in the current study. Multiple layers of neurons with nonlinear transfer functions allow the network to learn nonlinear relationships between input and output vectors [46]. Data normalization was done to both the input vectors and the target vectors in the data set.
When training multilayer networks, $70 \%$ of data was used for training, $15 \%$ was used to validate the network and to prevent overfitting [44], and the remaining $15 \%$ data were used as an independent test of network generalization. The data sets for training, validation, and testing are randomly chosen by the MATLAB NN toolbox. It was observed that the predictions of the trained neural network were good using either the algorithm-chosen test data set or an independent test data set. This was done to make sure the neural network models do not have the adaptability issues due to the data sets not chosen appropriately. This may happen when the data are biased. The training set was used for calculating the gradient and updating the weights and biases of the current network. The error from the validation set was monitored during the training. During the initial phase of training, errors in both training and validation sets tended to decrease $[47,48]$. Training automatically stopped when performance stopped improving, which is indicated by an increase in the mean square error of the validation samples [49]. The general network skeleton is shown in Fig. 1. The figure shows the $\mathrm{NN}$ model for three inputs and one output using two neurons and one hidden layer.

\section{Flare modeling design and variable selection for air- and steam-assisted flares}

Air- and steam-assisted flare data obtained from various data sources were collected to build neural network models with MATLAB. Two types of models were investigated:

- Performance inference models.

- Operation models.

Combustion efficiency (CE) and opacity are the main output variables, while Air assist (A)/steam (S), carbon to hydrogen molar ratio (CHR), carbon number $(\mathrm{CN})$, diameter (D), exit velocity of vent gas (V), crosswind velocity (U), net heating value of combustion zone $\left(\mathrm{NHV}_{\mathrm{CZ}}\right)$, and net heating value dilution parameter $\left(\mathrm{NHV}_{\mathrm{dil}}\right)$ are the independent variables in performance models. Conversely, air-/steam-assist or $\mathrm{NHV}_{\mathrm{CZ}} / \mathrm{NHV}_{\text {dil }}$ is the main output variable in operation models. All the inputs chosen for the models have a significance on their own and are interacting often. Assisted air or steam helps in suppressing smoke and mixing of the fuel and air. CHR or CN reflects the fuel species (methane, propane, propylene, ethylene) in the vent gas. CHR is calculated as an atomic ratio of carbon to hydrogen, while carbon number is the molar average of carbon atoms in the fuel species. The diameter of the flare stack depends on the type of flare since the available data represents both laboratory and industrial scale flares. The flare tip diameter should provide a large enough exit velocity so that the flame lifts off the flare tip 
Fig. 1 NN model skeleton using three inputs and two neurons

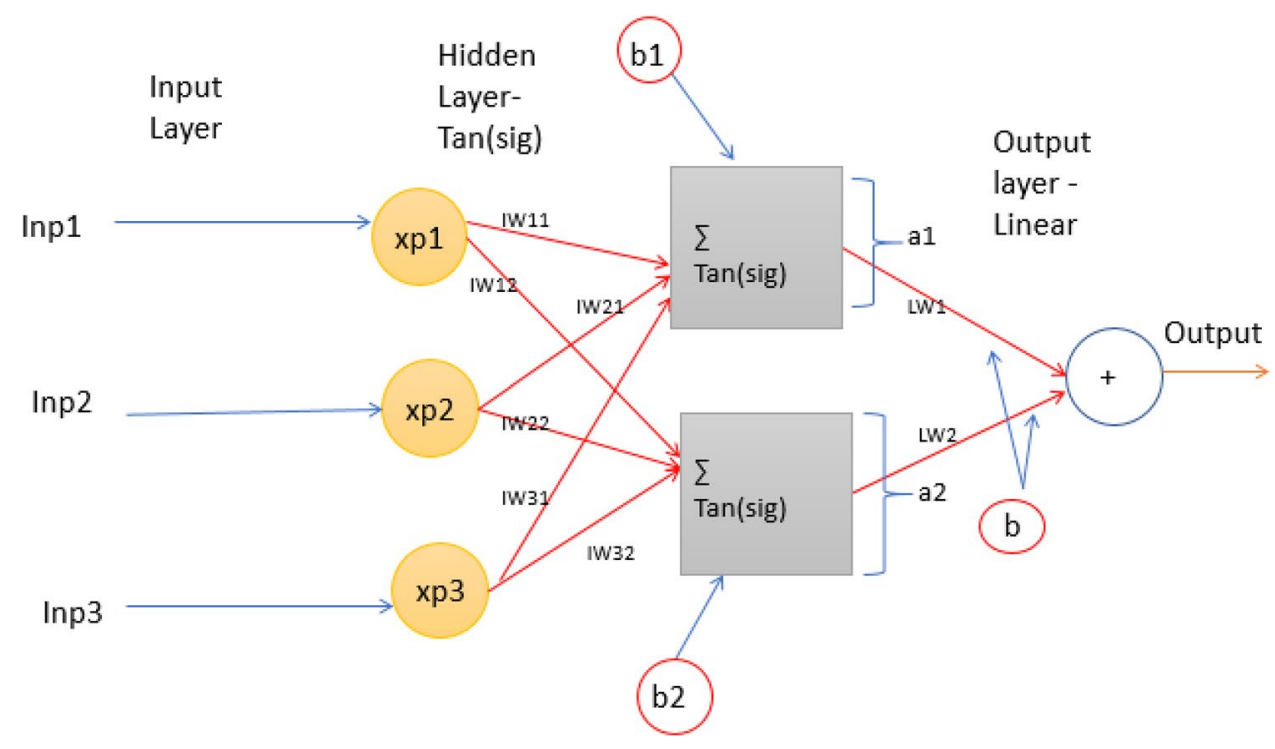

but not so large as to blow out the flare. It is critical to have an appropriate gas exit velocity (V) for an efficient flare while the crosswind velocity (U) takes into consideration the meteorological effect on the flame shape, downwash, and stability. High crosswind velocity can adversely affect the combustion efficiency of a flare while high flare tip velocity makes the flame less susceptible to the effects of crosswind. This interaction between $\mathrm{U}$ and $\mathrm{V}$ has been combined as a ratio, $\mathrm{R}(=\mathrm{U} / \mathrm{V})$, used as an input $[17-19,27-30,38,40]$. The heating value input, whether $\mathrm{NHV}_{\mathrm{CZ}}$ or $\mathrm{NHV}_{\mathrm{di}}$, is the most important input for the models because enough combustible material must be present to maintain flame stability and achieve a high efficiency.

Opacity and CE test data from 1983 to 2014 with soot emission or opacity observations were analyzed for air- and steam-assisted flares burning propylene, propane, methane, ethylene and typical refinery vent gas mixtures. Combustion efficiency data are all corrected for soot emission. Opacity data were generated based on soot emission, opacity index, flame shape, and flame diameter [28]. The \%CE and $\%$ Opacity data are transformed to Logit function (see below and Eq. 5 in Sect. 4) as the Logit distributions tend to be more uniform. Data normalization was done internally to both the input vectors and the target vectors by MATLAB NN Toolbox. No outliers were removed from the data set during the development of the $\mathrm{NN}$ models due to the need to cover a wide range of operating conditions. Combustion efficiency (in Logit normal form), which is bounded between 0 and 1 , was modeled. Since $100-\%$ CE is usually small, this variable, treated as log-normal Logit $(100-\% \mathrm{CE})$, has been used as an output variable for air-assisted flares; for steam-assisted flares, Logit \% Opacity has been used as an output because \% Opacity followed logit normal distribution, bounded by 0 and 1 .
The best models with these variables were selected based on the correlation coefficient, $\mathrm{R}$. The following equations show the definition for Combustion Zone Net Heating Value $\left(\mathrm{NHV}_{\mathrm{CZ}}\right)$ and $\mathrm{NHV}_{\mathrm{di}}$, respectively:

$N H V_{C Z}=\frac{N H V_{V G} * Q_{V G}+Q_{f} * N H V_{f}+Q_{p} * N H V_{p}}{Q_{V G}+x_{a} * Q_{a}+x_{s} * Q_{s}+Q_{p}}$,

$N H V_{d i l}=\frac{\left(N H V_{V G} * Q_{V G}+Q_{f} * N H V_{f}+Q_{p} * N H V_{p}\right) * D i a}{Q_{V G}+Q_{f}+x_{a} * Q_{a}+x_{s} * Q_{s}+Q_{p}}$,

where $Q_{\mathrm{vG}}$ volume flow rate of vent gas (scf/hr), $Q_{\mathrm{a}}$ volume flow rate of assisted air $(\mathrm{scf} / \mathrm{hr}), Q_{\mathrm{s}}$ volume flow rate of assisted steam (scf/hr), $Q_{\mathrm{p}}$ volume flow rate of pilot gas used (scf/hr), $\mathrm{NHV}_{\mathrm{VG}}$ net heating value of vent gas (btu/ $\mathrm{scf}), \mathrm{NHV}_{\mathrm{CZ}}$ net heating value of combustion zone (btu/scf), $\mathrm{NHV}_{\mathrm{P}}$ net heating value of pilot gas used (btu/scf), $x_{\mathrm{a}}$ effective fraction of air-assist that causes the dilution, $x_{\mathrm{s}}$ effective multiplier of steam assist (=1) and Dia is the diameter of flare stack (ft).

\section{Model summaries}

Neural network models were developed for the output variables Logit (100- \%CE) and Logit (\%Opacity) to fit the steam- and air-assisted flare data collected from 1983, 1984, 2010, and 2014 flare study reports. The definition of logit function for any variable $\mathrm{x}$ is given as follows:

$\operatorname{Logit}(x)=\log _{10} \frac{x}{(100-x)}$.

The operation models, which are essentially inversed performance models, were also developed using the same data 
where the assisted air/steam become output variables. The data ranges of steam- and air-assisted flare tests are shown in Tables 1 and 2, respectively.

\section{Steam-assisted flare models}

The final model summary for steam-assisted flare tests data, containing the response and input variables, number of neurons used, calculated variance (VE \%), Mean Absolute Error (MAE \%), and the correlation coefficient, $r$, is shown in Table 3. VE \%, MAE $\%$ and $r$ are calculated between experimental and calculated \% CE or \% Opacity in Table 3. The following equations show the formulas to calculate $\mathrm{VE}$ and MAE:

$\mathrm{MAE}=\frac{\sum_{1}^{n}\left|\exp _{i}-\operatorname{pred}_{i}\right|}{n \times \overline{\exp }} \times 100$,

$\mathrm{VE}=\left(1-\frac{\sum_{1}^{n}\left(\exp _{i}-\operatorname{pred}_{i}\right)^{2}}{\sum_{1}^{n}\left(\exp _{i}-\overline{\exp }\right)^{2}}\right) \times 100$
Figure 2 shows the comparison of experimental and predicted values for Logit (100- \% CE) model for steamassisted flares. The model in Fig. 2 uses $\mathrm{NHV}_{\mathrm{CZ}}, \mathrm{S}, \mathrm{U} / \mathrm{V}$, $\mathrm{U}, \mathrm{CHR}, \mathrm{CN}$, and $\mathrm{D}$ as inputs that can be used only when gas composition analysis can be done through the spectroscopy. Figure 3 shows the comparison of experimental and predicted values for Logit (\% Opacity) models for steamassisted flares. Logit opacity model uses $\mathrm{NHV}_{\mathrm{CZ}}$ and $\mathrm{U} / \mathrm{V}$ in the model used in Fig. 3. Both Logit models for opacity and CE have a correlation coefficient of greater than 0.97 . Figure 4 shows model for assisted steam data as $\log (\mathrm{S})$ as output against experimental data. $70 \%$ data is used in training and $15 \%$ each is used in validation and testing in all the models. Figure 5 shows the contours of $\mathrm{CE}$ on $\mathrm{R}$ vs $\mathrm{NHV}_{\mathrm{CZ}}$ at a fixed $\mathrm{D}(2 \mathrm{ft}), \mathrm{S}(110 \mathrm{lb} / \mathrm{MMBTU})$ and $\mathrm{U}(8 \mathrm{ft} / \mathrm{s})$ values. From Fig. 5 it was observed that there is almost no flame at very low $\mathrm{R}$ and low $\mathrm{NHV}_{\mathrm{CZ}}$. With an increase in $\mathrm{R}$ at lower $\mathrm{NHV}_{\mathrm{CZ}}(100-1000 \mathrm{BTU} / \mathrm{scf})$, the $\mathrm{CE}$ was found to be high (90\%). For all R beyond 15, the model predicted a good $\mathrm{CE}$ at the given $\mathrm{S}$ and $\mathrm{U}$ values. Figure 6 shows the contour plot for Opacity over $\mathrm{NHV}_{\mathrm{CZ}}$ vs R. The dark region represents highly smoking flare while the light regions represent very low to no sooting flare. The contour lines of $2 \%$ (SLF) and 3\% (ISP) Opacity can be seen in Fig. 6. This

Table 1 Test data ranges for steam-assisted flares [19, 27, 29, 30, 32, 51, 52]

\begin{tabular}{|c|c|c|c|c|c|c|c|c|c|c|}
\hline \multirow[t]{2}{*}{ \%Opacity } & \multicolumn{2}{|l|}{$\mathrm{D}(\mathrm{ft})$} & \multicolumn{2}{|l|}{ CHR } & \multicolumn{2}{|c|}{$\mathrm{NHV}_{\mathrm{CZ}}(\mathrm{BTU} / \mathrm{scf})$} & \multicolumn{2}{|c|}{ S (lb/MMBTU) } & \multicolumn{2}{|l|}{$V(\mathrm{ft} / \mathrm{s})$} \\
\hline & Range & Max. value & Range & Max. value & Range & Max. value & Range & Max. value & Range & Max. value \\
\hline 0.0016-99.99 & $0.125-3$ & 3 & $0.2-0.5$ & 0.5 & $90-2140$ & 2140 & $0-514$ & 514 & $0.2-428$ & 428 \\
\hline
\end{tabular}

*280 data points used in the models from all sources

Table 2 Test data ranges for air-assisted flares [19, 28, 32, 51]

\begin{tabular}{|c|c|c|c|c|c|c|c|c|c|c|}
\hline \multirow[t]{2}{*}{ \% Opacity } & \multicolumn{2}{|l|}{$\mathrm{D}(\mathrm{ft})$} & \multicolumn{2}{|l|}{ CHR } & \multicolumn{2}{|c|}{$\mathrm{NHV}_{\text {dil }}\left(\mathrm{BTU} / \mathrm{ft}^{2}\right)$} & \multicolumn{2}{|c|}{ A (lb/MMBTU) } & \multicolumn{2}{|l|}{$\mathrm{V}(\mathrm{ft} / \mathrm{s})$} \\
\hline & Range & Max. value & Range & Max. value & Range & Max. value & Range & Max. value & Range & Max. value \\
\hline $0.0013-55.95$ & $0.13-2$ & 2 & $0.2-0.5$ & 0.5 & $5.7-1930$ & 1930 & $0-26,238$ & 26,238 & $0.36-72$ & 72 \\
\hline
\end{tabular}

*102 data points used in the models from all sources

Table 3 Result summary of steam-assisted flares

\begin{tabular}{|c|c|c|c|c|c|c|}
\hline Response & Input & \# Neurons & $R$ & MAE (\%) & $\operatorname{VE}(\%)$ & $\begin{array}{l}\text { GC meas- } \\
\text { urement } \\
\text { required? }\end{array}$ \\
\hline Logit (100- \%CE) & $\mathrm{NHV}_{\mathrm{CZ}}, \mathrm{S}, \mathrm{R}, \mathrm{U}, \mathrm{D}$ & 7 & 0.97 & 1.88 & 93.41 & No \\
\hline Logit (100- \%CE) & $\mathrm{NHV}_{\mathrm{CZ}}, \mathrm{S}, \mathrm{R}, \mathrm{U}, \mathrm{D}, \mathrm{CHR}, \mathrm{CN}$ & 7 & 0.98 & 1.39 & 96.71 & Yes \\
\hline Logit (\%Opacity) & $\mathrm{NHV}_{\mathrm{CZ}}, \mathrm{R}$ & 5 & 0.99 & 1.22 & 98.35 & No \\
\hline Logit (\%Opacity) & $\mathrm{NHV}_{\mathrm{CZ}}, \mathrm{R}, \mathrm{CHR}$ & 5 & 0.99 & 1.28 & 98.79 & Yes \\
\hline $\log S$ & $\mathrm{NHV}_{\mathrm{vg}}, \mathrm{NHV}_{\mathrm{CZ}}, \operatorname{Logit}(\%$ Opacity) & 2 & 0.92 & - & 89.78 & No \\
\hline
\end{tabular}

*r, VE \% and MAE \% are calculated between experimental and calculated \%CE or \%Opacity; 280 data points were used in the models 
Fig. 2 Experiment vs. predicted Logit(100-\%CE) output with seven neurons for steamassisted flares
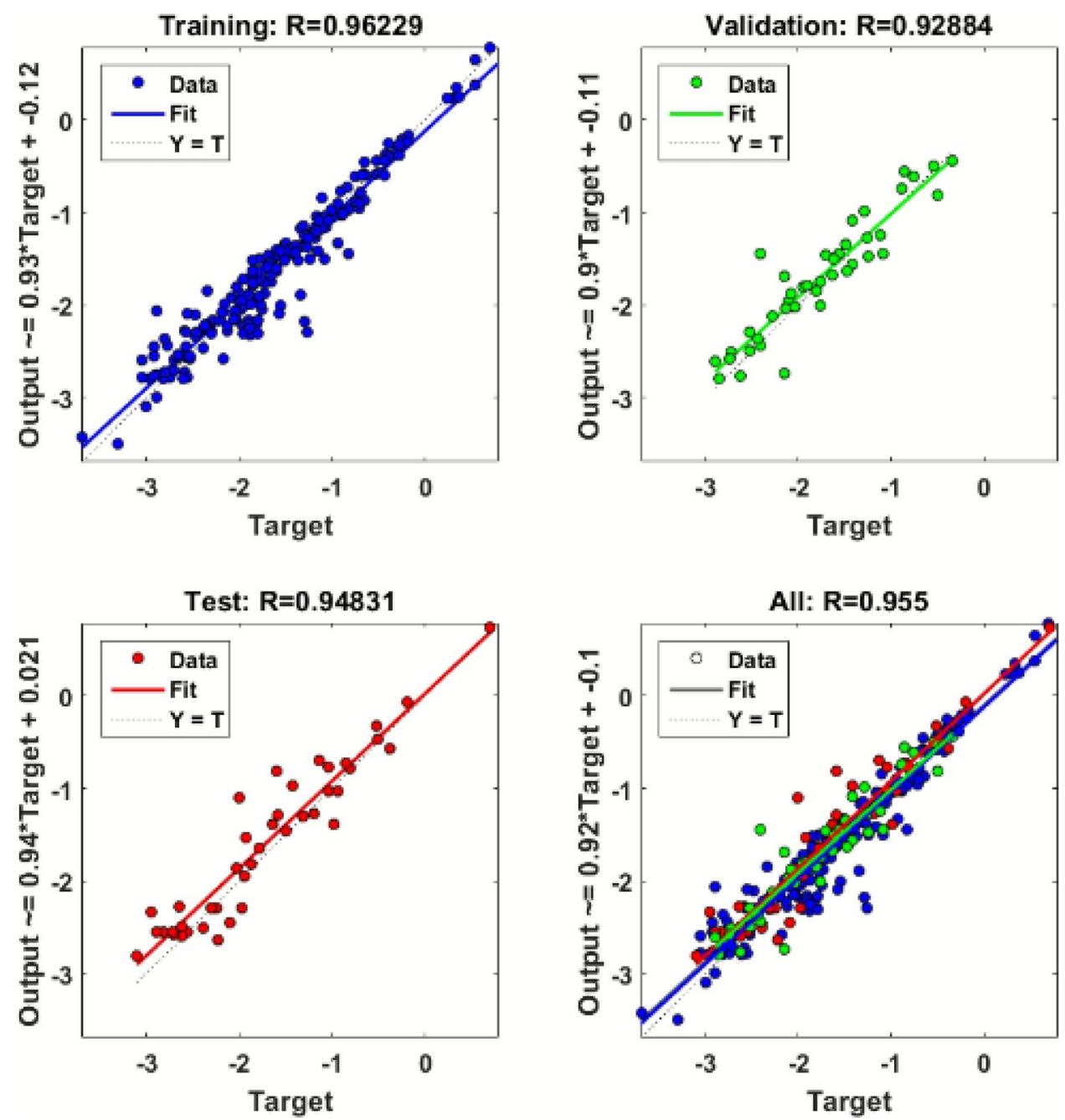

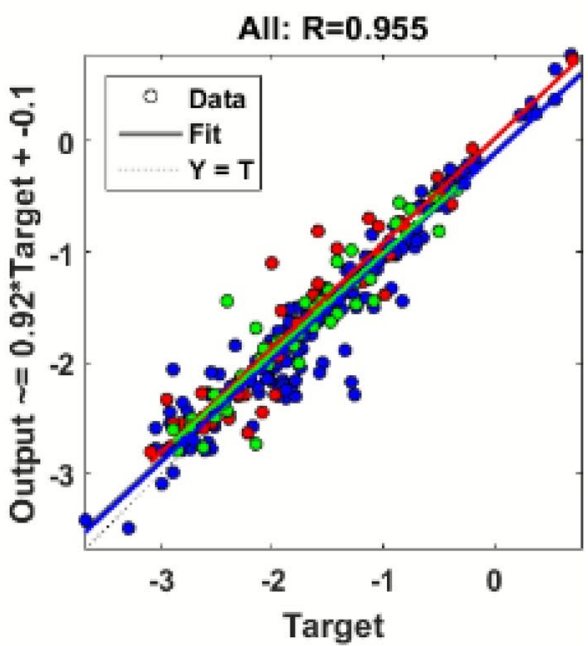

plot demonstrates that at $\mathrm{NHV}_{\mathrm{CZ}}$ below $1050 \mathrm{BTU} / \mathrm{scf}$ and $\mathrm{R}$ below 15 , the opacity is very high. At $\mathrm{R}$ greater than 15 , smoke is reduced. This is the same $\mathrm{R}$ value beyond which CE increases simultaneously as seen in Fig. 5.

\section{Air-assisted flare models}

Figures 7 and 8 show the comparison of experimental and predicted values for Logit (100- \%CE) and Logit (\%Opacity) models, respectively, for air-assisted flares. Figure 9 shows the inverse model for air assist ( $\log \mathrm{A})$ as an output between the predicted and experimental data.

The final model summary for air-assisted flare tests data, containing the response and input variables, number of neurons used, the calculated variance (VE \%), MAE \% and the correlation coefficient, $r$ is shown in Table 4.

Figure 10 shows the contours of $\mathrm{CE}$ on $\mathrm{R}$ vs $\mathrm{NHV}_{\mathrm{dil}}$ at a fixed D (1.5ft), A (8000 lb/MMBTU), and CHR (0.4) values. The same plot can be drawn at a different set of values but it's important to choose typical values, like middle of the range or near ISP values to show the trends of the models. From Fig. 10, it is seen that CE is high at low $\mathrm{R}$ but decreases sharply (99\% to $89 \%$ ) with increase in $\mathrm{R}$, at lower $\mathrm{NHV}_{\mathrm{dil}}\left(<100 \mathrm{BTU} / \mathrm{ft}^{2}\right)$. CE is found to be high $(97 \%)$ for $\mathrm{NHV}_{\text {dil }}$ greater than $1200 \mathrm{BTU} / \mathrm{ft}^{2}$ for all R. Figure 11 shows the contours of CE over A vs $\mathrm{NHV}_{\text {dil }}$ at a fixed D (1.5ft), R (15) and CHR (0.4) values. From the trend of the contours it is observed that over-aeration leads to low CE especially at lower $\mathrm{NHV}_{\text {dil }}$ and at high $\mathrm{NHV}_{\text {dil }}$, CE can still be high until 16,000 lb/MMBTU of air assist, beyond which the efficiency drops. Contour plot for Opacity over $\mathrm{NHV}_{\mathrm{vg}}$ vs A is shown in Fig. 12. The dark region represents a highly sooting flare while the lighter regions represent a very low sooting to smokeless flare. Of the 5 input variables of opacity model, D (1.5ft), V $(1 \mathrm{ft} / \mathrm{s})$, and $\mathrm{U}(10 \mathrm{ft} / \mathrm{s})$ have been fixed. The contour lines of 2\% (SLF) and 3\% (ISP) Opacity can be seen in Fig. 12. This plot confirms that over-aeration not only decreases CE but also makes the flare smokier, particularly at low $\mathrm{NHV}_{\text {dil }} / \mathrm{NHV}_{\mathrm{vg}}$. 
Fig. 3 Experiment vs. predicted Logit(\%Opacity) output with five neurons for steam-assisted flares
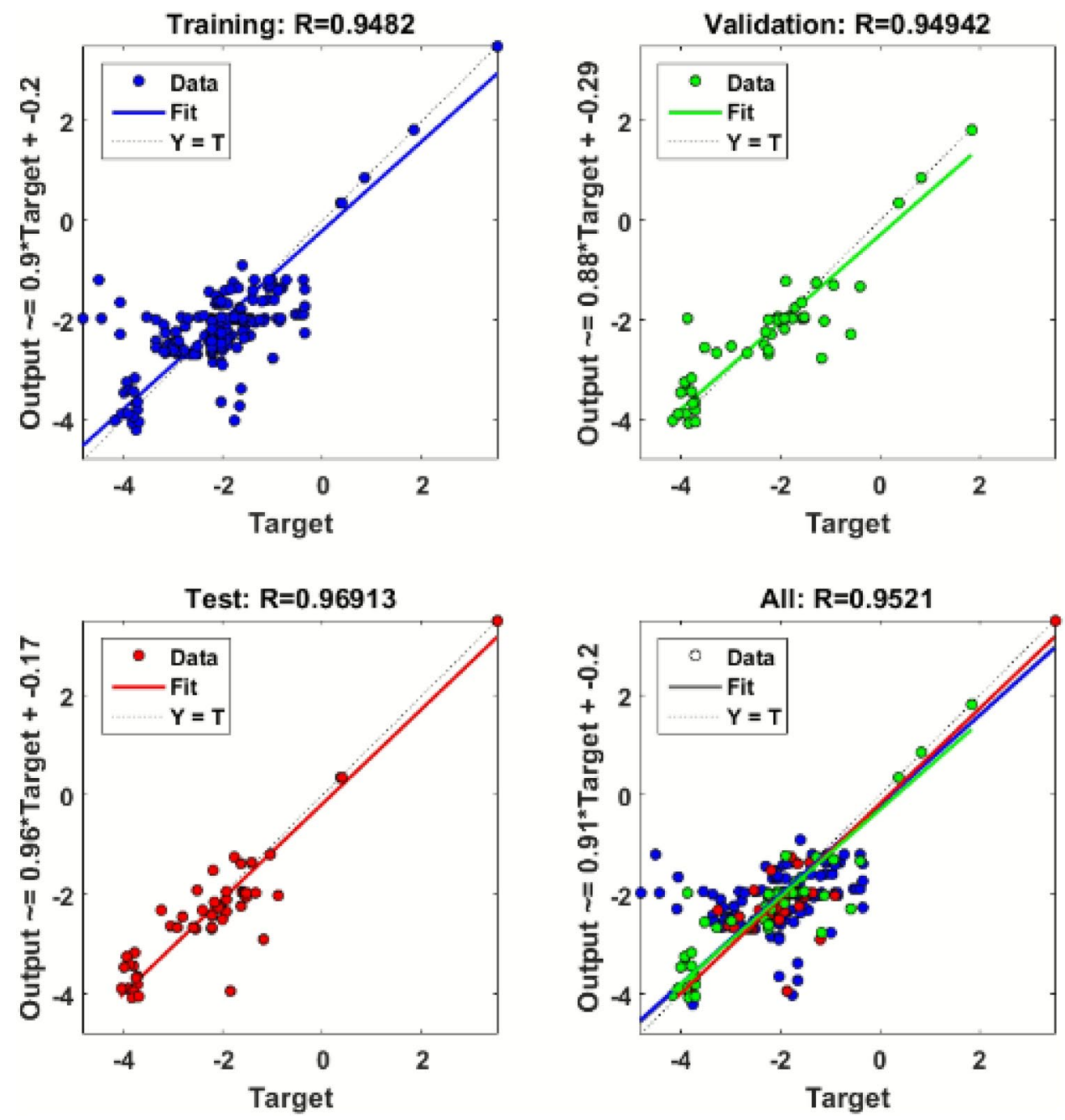

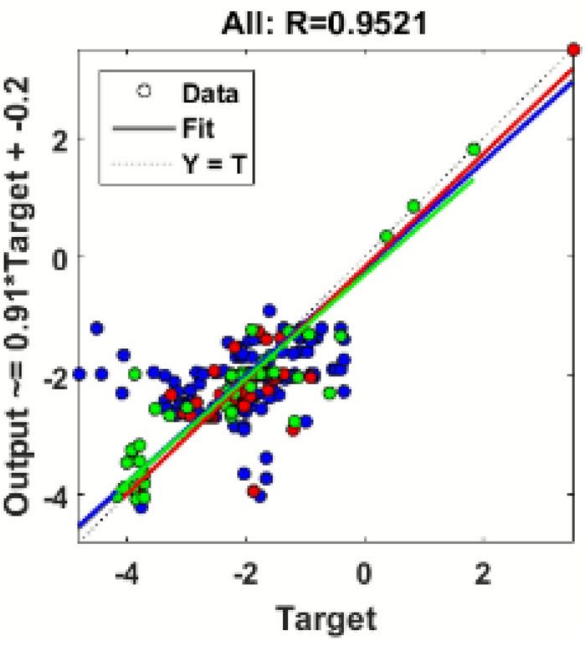

All the performance criteria (r, VE, MAE) were calculated for the original variables (\% CE or \% Opacity) from the logit functions of models by converted back. These results indicated that there was a good agreement between the experimental and predicted values. Artificial neural network models developed in this study can be used further to determine the amount of air/steam assistance to achieve the desired CE. NN models presented in this study confirm the considerable value of the $\mathrm{NN}$ based approach in predicting the flare performance.

\section{Application of the NN models for flare setpoint determination}

Current control practices only address opacity to satisfy the EPA requirements. Operators tend to over-steam or overaerate to suppress smoke at the expense of combustion efficiency (CE). Stand-by mode operations with low vent gas flow rates and low heating values often lead to (Destruction Removal Efficiency) DRE/CE below their expected values of
98\%/96.5\%. Refineries need to monitor and maintain minimum combustion zone net heating value $\left(\mathrm{NHV}_{\mathrm{CZ}}\right)$ as per EPA's flare MACT rule [20,53]. Incipient smoke point (ISP) is widely recognized as the condition for most efficient burning. Determining the setpoints for flare operations at ISP and Smokeless flaring (SLF) operations is a major criterion to make flares compliant with the EPA regulations. Determining the setpoint (amount of steam/air/make-up fuel required) at the ISP and for smokeless flaring (SLF) has been performed as a part of this study. Desirable operating inputs can be set for the ISP $\left(\mathrm{NHV}_{\mathrm{dil}} \geq 22 \mathrm{BTU} / \mathrm{ft}^{2} \&\right.$ Opacity $\leq$ Opacity ISP) and for smokeless flaring with $\mathrm{NHV}_{\mathrm{dil}} \geq 22 \mathrm{BTU} / \mathrm{ft}^{2}$ and

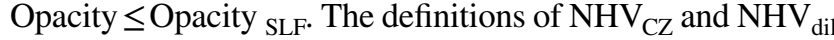
have been shown in Eqs. 3 and 4, respectively [16].

The criteria for air-assisted flares at the ISP is determined as $\mathrm{NHV}_{\mathrm{dil}} \geq 22 \mathrm{BTU} / \mathrm{ft}^{2}$ and Opacity $=3 \%$ and for smokeless flaring is $\mathrm{NHV}_{\mathrm{dil}} \geq 22 \mathrm{BTU} / \mathrm{ft}^{2}$ and opacity $=2 \%[55,56]$. The same criteria for steam-assisted flares at the ISP is determined to be $\mathrm{NHV}_{\mathrm{CZ}} \geq 270 \mathrm{BTU} / \mathrm{scf}$ and Opacity $=3 \%$ while for smokeless flaring the criteria is $\mathrm{NHV}_{\mathrm{CZ}} \geq 270 \mathrm{BTU} / \mathrm{scf}$ and Opacity $=2 \%$. The developed NN models have been used 
Fig. 4 Experiment vs. predicted Log (steam assist) (lb/MMBTU) as output with two neurons for steam-assisted flares
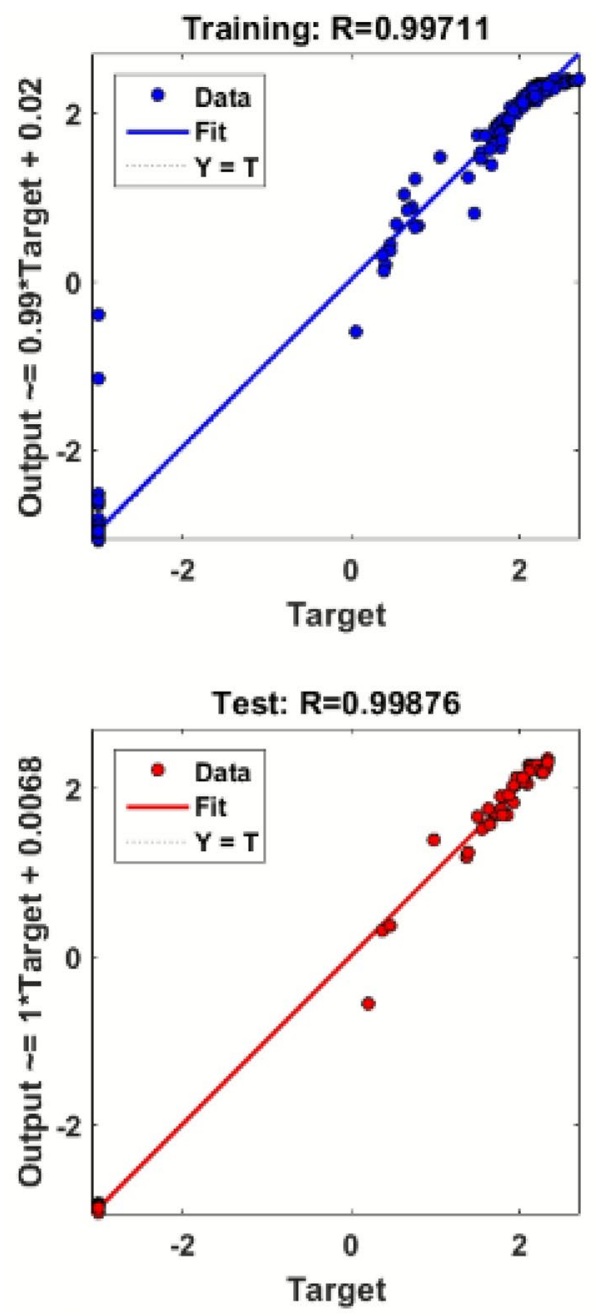
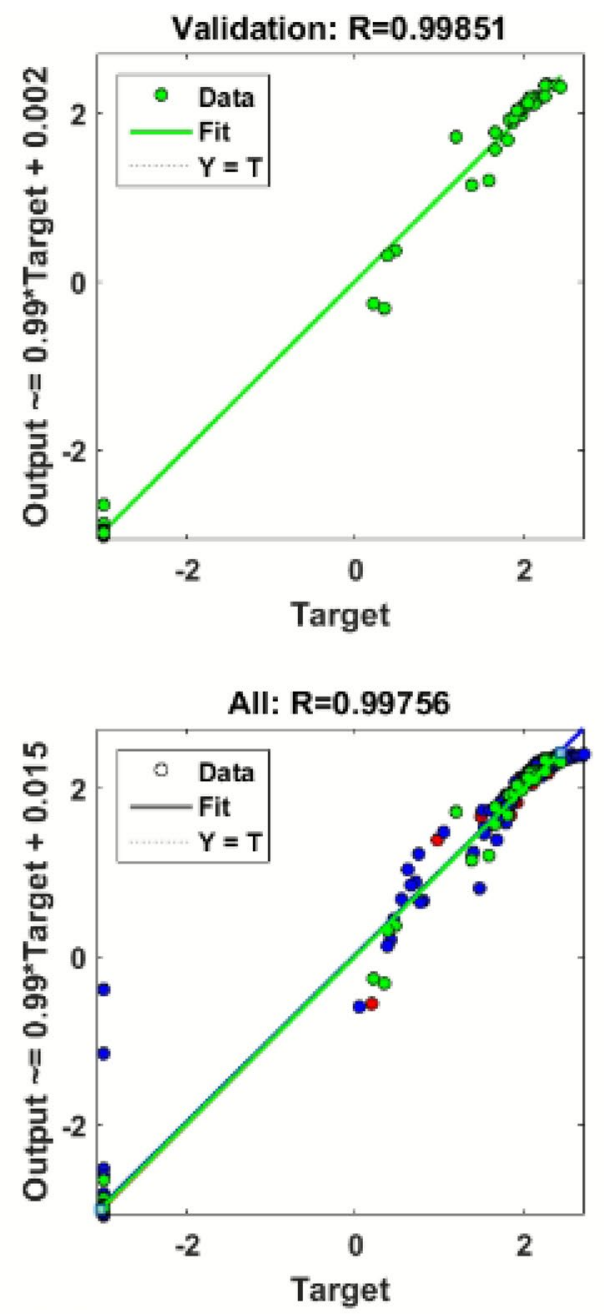

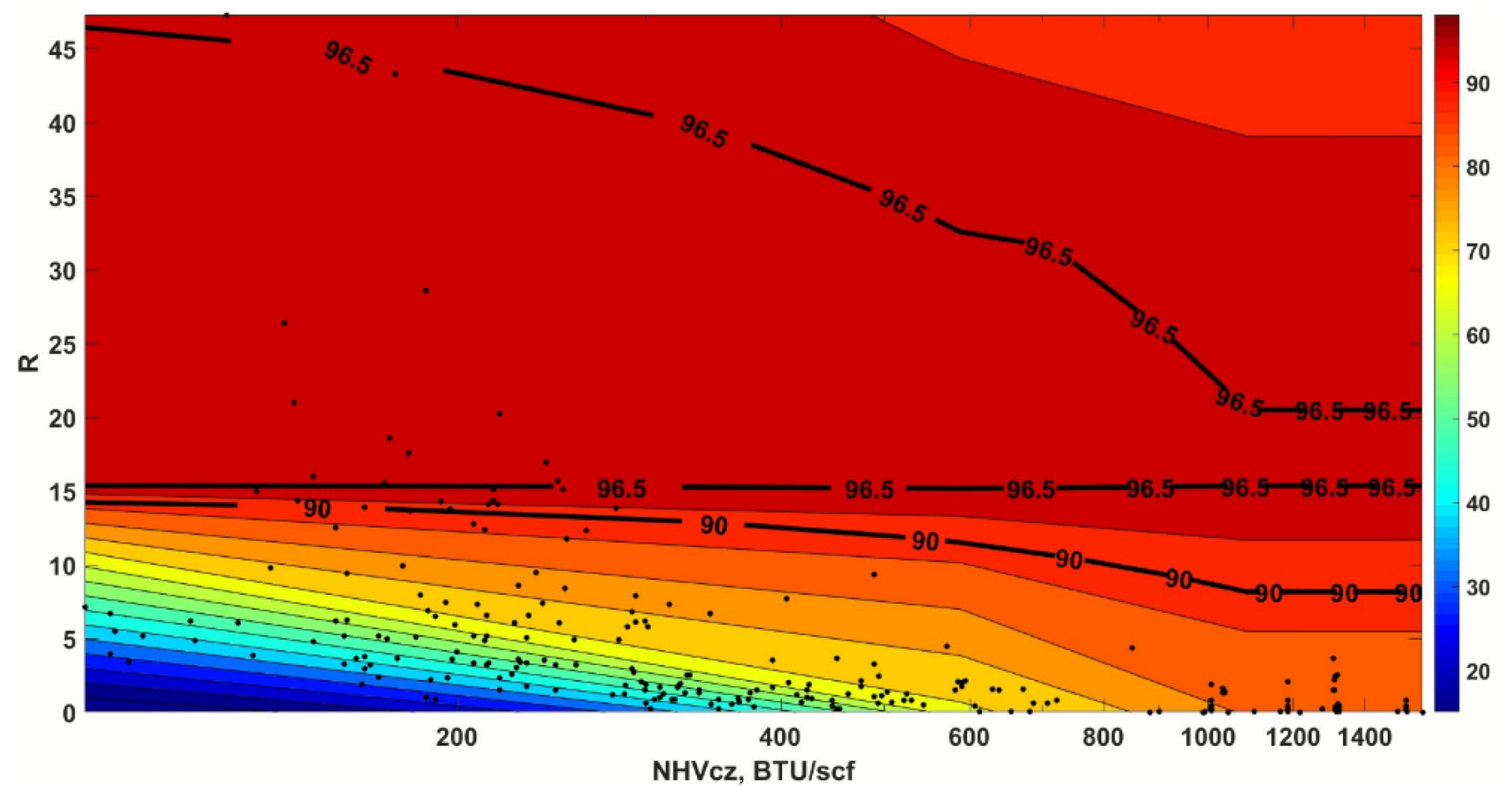

Fig. 5 2D contour plot of \% CE on $\mathrm{NHV}_{\mathrm{CZ}}$ vs R for steam-assisted flares at fixed D (2 ft), U (8 ft/s) and S (110 lb/MMBTU) 


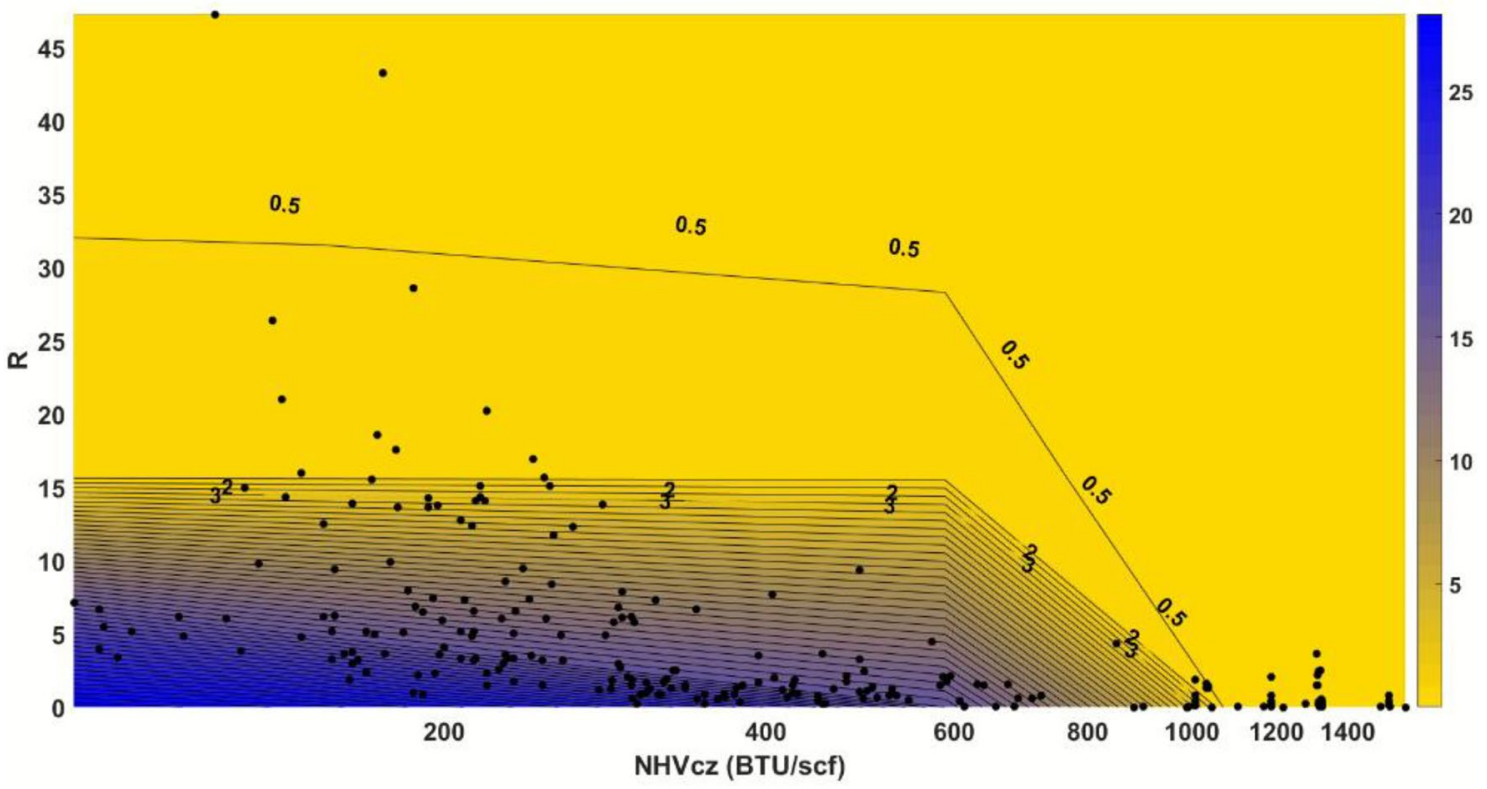

Fig. 6 2D contour plot of \% Opacity on $\mathrm{NHV}_{\mathrm{CZ}}$ vs R for steam-assisted flares

Fig. 7 Experiment vs. predicted Logit (100- \%CE) as output with two neurons for air-assisted flares
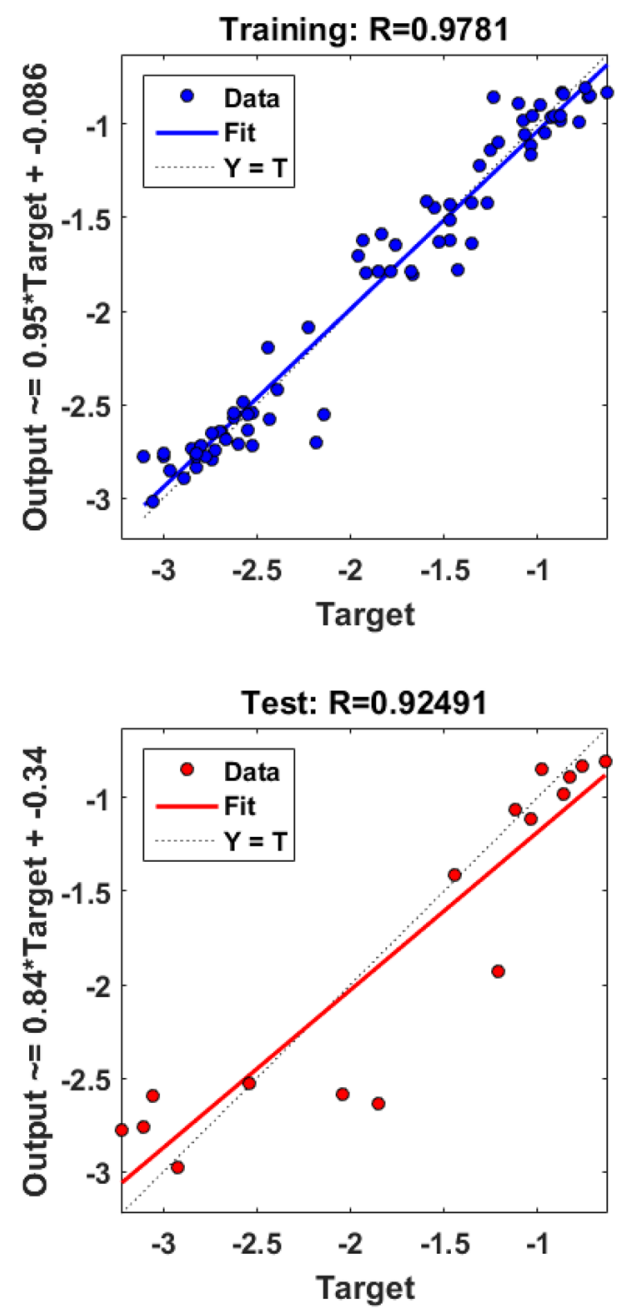
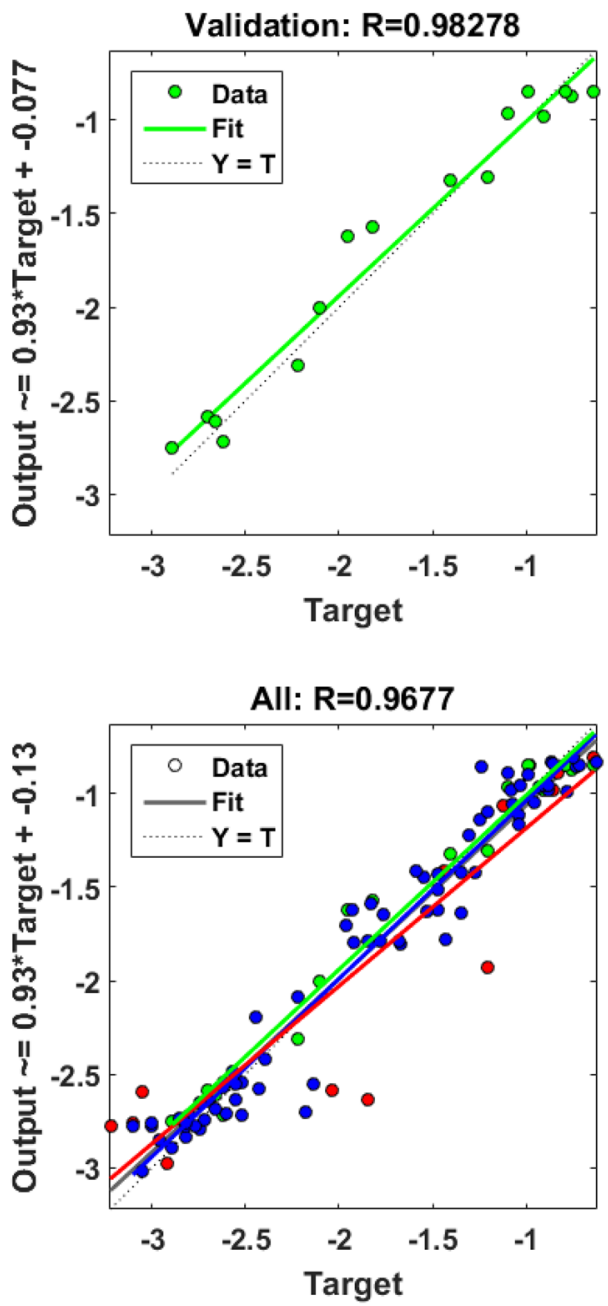
Fig. 8 Experiment vs. predicted Logit(\%Opacity) as output with six neurons for air-assisted flares
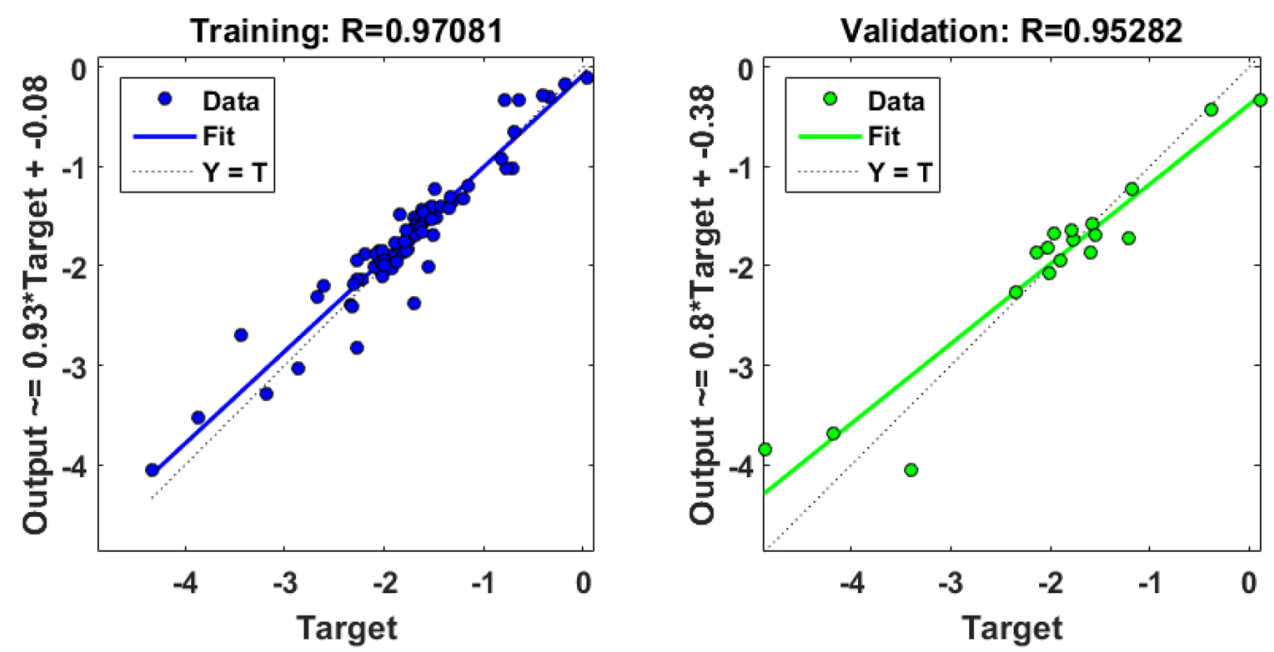

Test: $\mathbf{R}=\mathbf{0 . 9 6 0 5 8}$

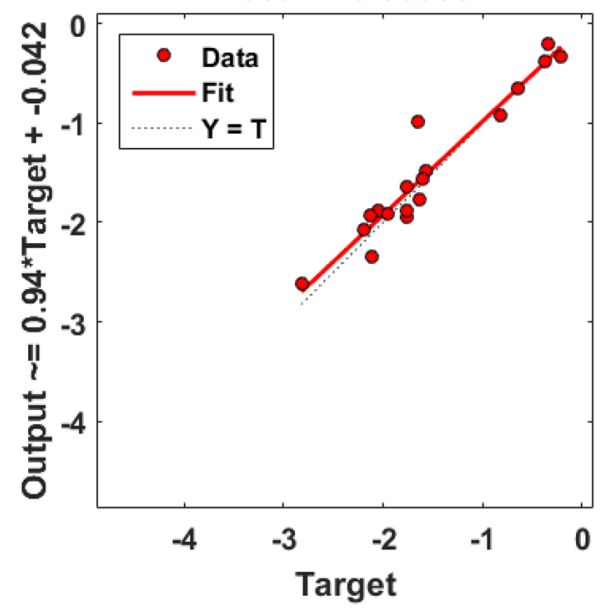

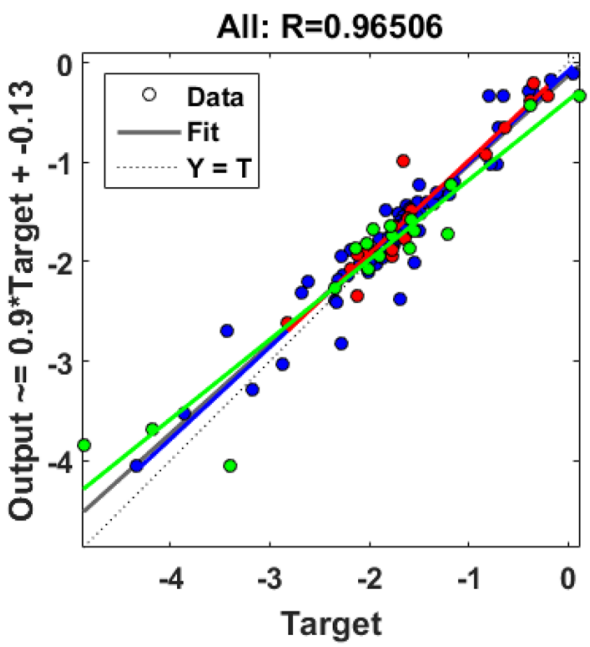

at the ISP and SLF to determine the operation set points in compliance with the current EPA regulations. The specific set point of a manipulated variable (steam-/air-assisted or makeup fuel or $\mathrm{NHV}_{\mathrm{CZ}}$ ) was solved by specifying opacity and $\mathrm{NHV}_{\mathrm{CZ}} \geq 270 \mathrm{BTU} / \mathrm{scf}$ or $\mathrm{NHV}_{\mathrm{dil}} \geq 22 \mathrm{BTU} / \mathrm{ft}^{2}$ for steam- and air-assisted flare data, respectively [55, 57]. For cases that do not satisfy the minimum heating value requirement, make-up fuel needed to be added to increase it to the minimum required value $\left(\mathrm{NHV}_{\mathrm{CZ}}=270 \mathrm{BTU} / \mathrm{scf}\right.$ or $\mathrm{NHV}_{\mathrm{dil}}=22 \mathrm{BTU} / \mathrm{ft}^{2}$. Natural gas $\left(\mathrm{NHV}_{\mathrm{f}}=914 \mathrm{BTU} / \mathrm{scf}\right)$ is generally used as the make-up fuel for these gases.

Consider a steam flare:

$$
\begin{aligned}
& \mathrm{CE}=f\left(\mathrm{NHV}_{\mathrm{CZ}}, \mathrm{S}\right), \\
& \mathrm{S}=g\left(\mathrm{NHV}_{\mathrm{vg}}, \mathrm{NHV}_{\mathrm{CZ}}, \% \text { Opacity }\right), \\
& \mathrm{NHV}_{\mathrm{CZ}}=h\left(\mathrm{NHV}_{\mathrm{vg}}, \mathrm{F}, \mathrm{S}\right) .
\end{aligned}
$$

Given $\mathrm{NHV}_{\mathrm{vg}}$ is a measured disturbance variable, $\mathrm{NHV}_{\mathrm{CZ}}=270 \mathrm{BTU} / \mathrm{scf}$ and opacity $=3 \%$ are specified at the ISP and the equations were solved in excel using the NN model equations to obtain the desired $\mathrm{S}, \mathrm{F}$, and $\mathrm{NHV}_{\mathrm{CZ}}$. The same methodology has been implemented to determine the make-up fuel and assisted steam/air for smokeless flaring, which has a lower opacity specification, $2 \%$.

The model parameters for the ISP and SLF have been exported to excel and then solved using the methodology to find the assistance air required to achieve the specific criteria of $\mathrm{NHV}_{\mathrm{dil}} \geq 22 \mathrm{BTU} / \mathrm{ft}^{2}$ and opacity $=3 \%$ at the ISP and $\mathrm{NHV}_{\text {dil }} \geq 22 \mathrm{BTU} / \mathrm{ft}^{2}$ and opacity $=2 \%$ for SLF. The opacity settings are based on the average \% Opacity of the ISP characterization $[27,28]$ and are used here for illustration purposes. Since states (or countries) have various definitions of \% Opacity for smoky flares (visible emissions), users can adapt the numbers (e.g., 5\%, 10\%, etc. for \% Opacity at the ISP) to comply with the regulatory requirements. Logit(100-\%CE) model is then used to find the final CE at the ISP. 
Fig. 9 Experiment vs. predicted air assist (lb/MM BTU) as output with 3 neurons for airassisted flares

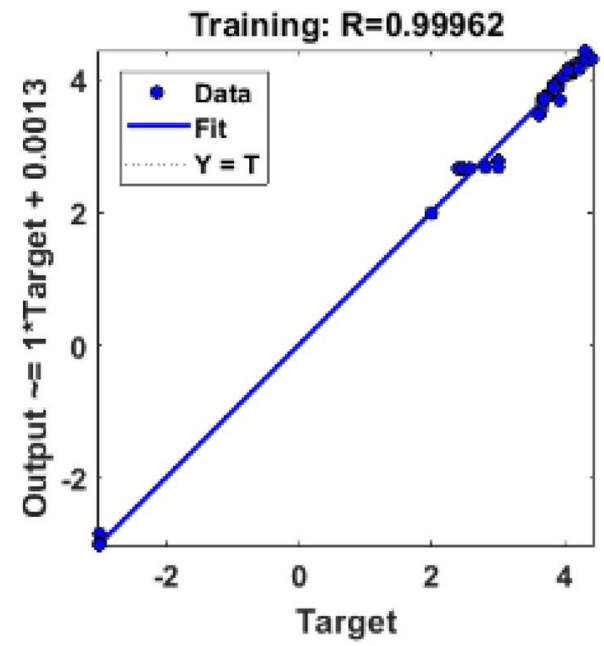

Test: $\mathbf{R}=\mathbf{0 . 9 9 9 3 4}$

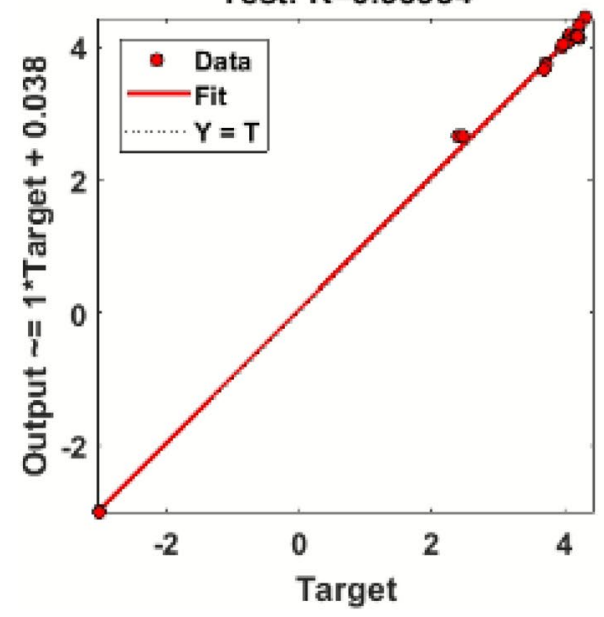

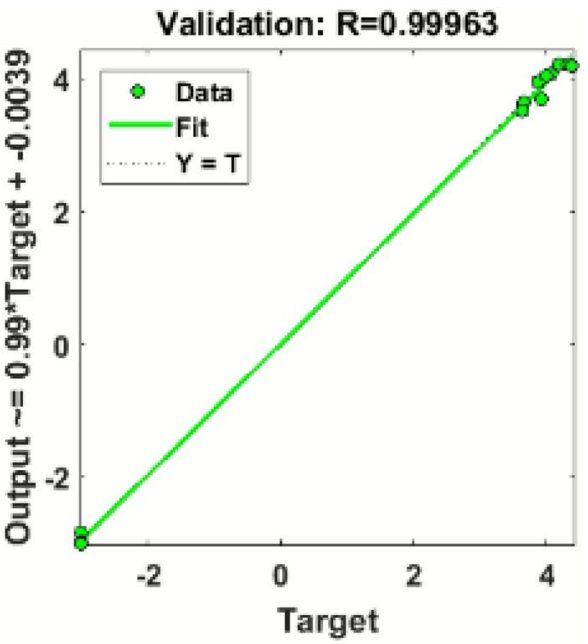

All: $\mathrm{R}=0.99958$

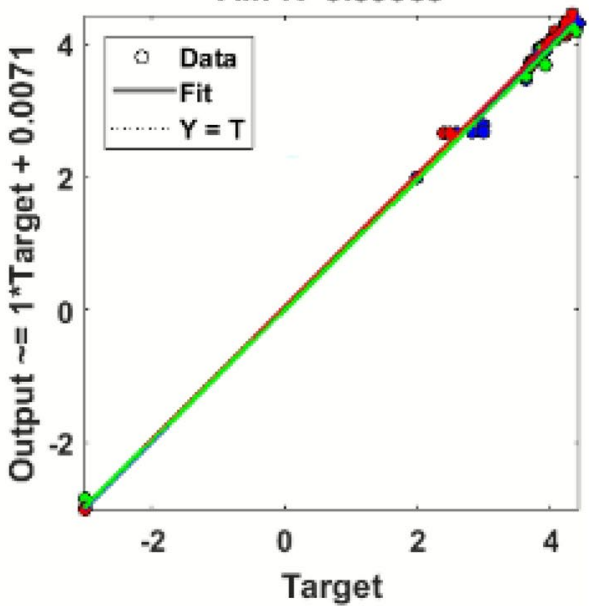

Table 4 Result summary of air-assisted flares

\begin{tabular}{|c|c|c|c|c|c|c|}
\hline Response & Input & \# Neurons & $\mathrm{R}$ & MAE (\%) & $\operatorname{VE}(\%)$ & $\begin{array}{l}\text { GC meas- } \\
\text { urement } \\
\text { required? }\end{array}$ \\
\hline Logit (100- \%CE) & $\mathrm{U}, \mathrm{V}, \mathrm{A}, \mathrm{NHV}_{\mathrm{dil}}, \mathrm{D}$ & 5 & 0.95 & 1.17 & 88.23 & No \\
\hline Logit (100- \%CE) & $\mathrm{R}, \mathrm{A}, \mathrm{NHV}_{\mathrm{dil}}, \mathrm{D}, \mathrm{CHR}$ & 2 & 0.95 & 1.08 & 89.98 & Yes \\
\hline Logit (\%Opacity) & $\mathrm{U}, \mathrm{V}, \mathrm{A}, \mathrm{NHV}_{\mathrm{vg}}, \mathrm{D}$ & 6 & 0.96 & 1.75 & 91.71 & No \\
\hline Logit (\%Opacity) & $\mathrm{U}, \mathrm{V}, \mathrm{A}, \mathrm{NHV}_{\mathrm{vg}}, \mathrm{D}, \mathrm{CHR}$ & 4 & 0.98 & 0.79 & 96.46 & Yes \\
\hline $\log A$ & $\mathrm{NHV}_{\mathrm{vg}}, \mathrm{NHV}_{\mathrm{dil}}, \operatorname{Logit}(\%$ Opacity $)$ & 3 & 0.96 & - & 93.34 & No \\
\hline
\end{tabular}

*r, VE \% and MAE \% are calculated between experimental and calculated \% CE or \%Opacity; 102 data points were used in the models

The predicted air assist, $\mathrm{CE}$, and $\mathrm{NHV}_{\mathrm{dil}}$ at the ISP has been compared against those for smokeless flaring (SLF) data in Figs. 13, 14 and 15, respectively. Both $\mathrm{NHV}_{\text {dil }}$ and $\mathrm{NHV}_{\mathrm{CZ}}$ have make-up fuel in the numerator and $\mathrm{A}$ or $\mathrm{S}$ in the denominator and hence will lead to multiple solutions satisfying the inequality constraints $\left(\mathrm{NHV}_{\mathrm{dil}} \geq 22 \mathrm{BTU} / \mathrm{scf}\right.$ or $\mathrm{NHV}_{\mathrm{CZ}} \geq 270 \mathrm{BTU} / \mathrm{scf}$ ). However, from the economic standpoint, i.e., to minimize the use of make-up fuel and steam (or air), $Q_{\mathrm{f}}=0$ is always practiced.

The predicted air assistance has been significantly lowered while increasing the $\mathrm{NHV}_{\text {dil }}$ and CE simultaneously for all the test cases. CE is found to be higher than the experimental data for all the test cases. None of the air-assisted flare tests required any external make-up fuel to determine 


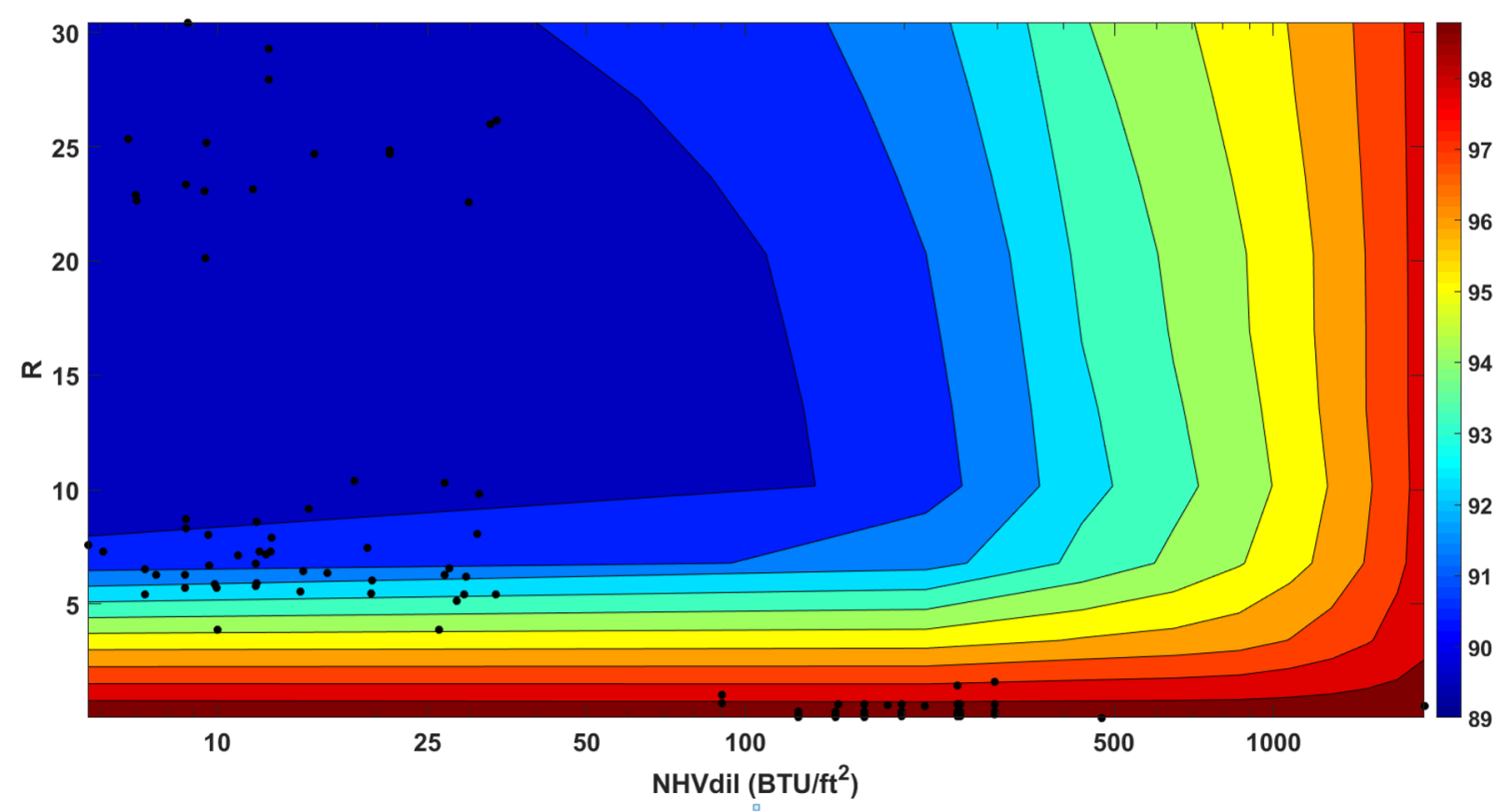

Fig. 10 2D contour plot of \% CE on $\mathrm{NHV}_{\text {dil }}$ vs R for air-assisted flares at fixed D (1.5ft), A (8000 lb/MMBTU) and CHR (0.4)

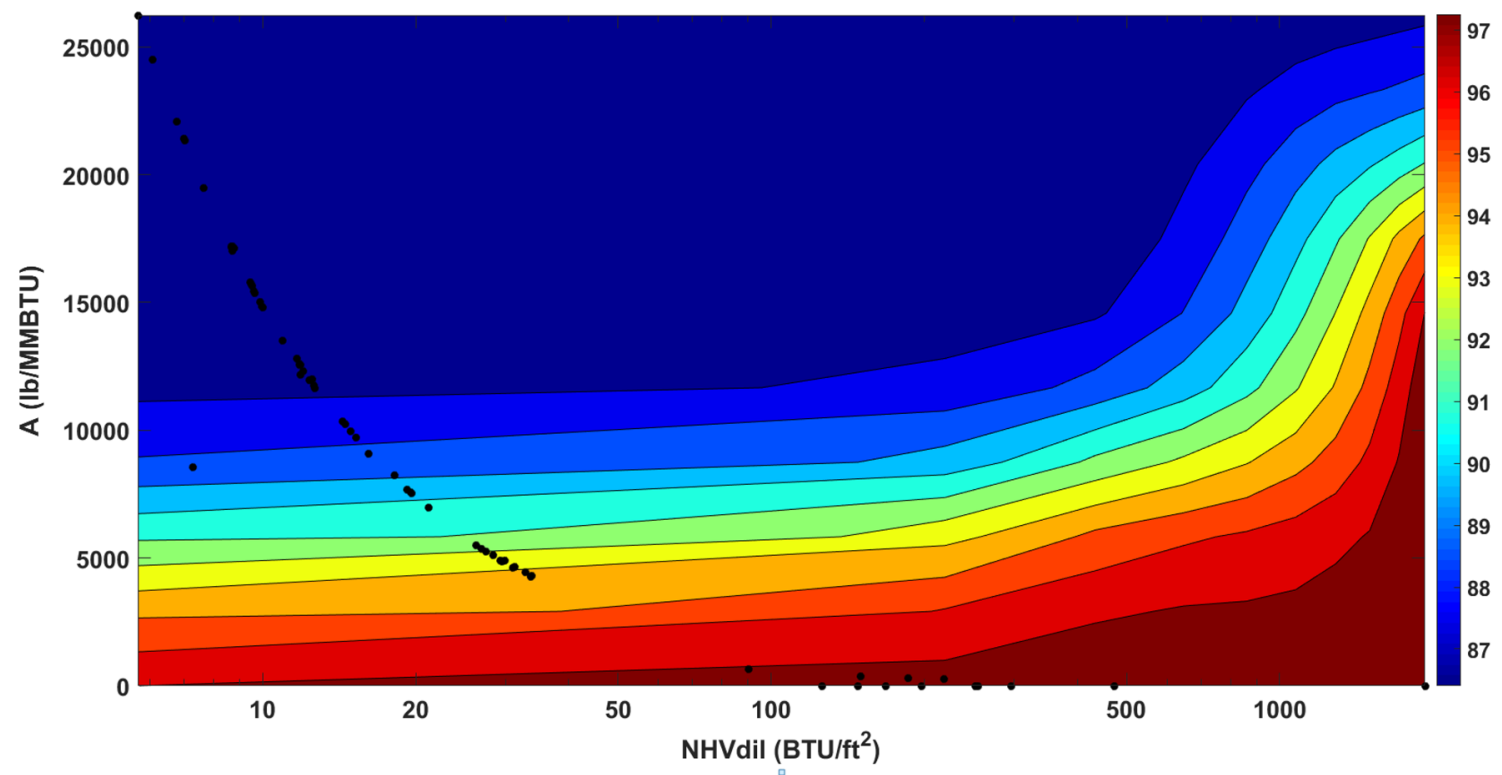

Fig. $112 \mathrm{D}$ contour plot of \% $\mathrm{CE}$ on $\mathrm{NHV}_{\text {dil }}$ vs A for air-assisted flares at fixed D (1.5ft), R (15) and CHR (0.4)

the setpoints for ISP or for SLF. For cases where make-up fuel would be required, it is important to add the make-up fuel into the calculation of $\mathrm{NHV}_{\mathrm{vg}}$, req since $\mathrm{NHV}_{\mathrm{vg}}$, req will become the new $\mathrm{NHV}_{\mathrm{vg}}$ for further calculation of required steam and $\mathrm{CE}$ till convergence. The make-up fuel used in the SP determination is natural gas to increase the net heating value of the vent gases.

The ISP characterization results by Chen et al. for steamassisted flares show that about 16-211 lb/MMBTU of steam and 342-1374 BTU/scf of $\mathrm{NHV}_{\mathrm{vg}, \text { req }}$ at the ISP whereas the NN model recommends 0-94 lb/MMBTU of steam and $\mathrm{NHV}_{\mathrm{vg}, \mathrm{req}}$ is the same as the experimental $\mathrm{NHV}_{\mathrm{vg}}(348-2350$ BTU/scf). Similarly, the ISP characterization results for airassisted flares show that about 4431-8609 lb/MMBTU of air and 297-1157 BTU/scf of $\mathrm{NHV}_{\mathrm{vg}, \text { req }}$ at the ISP whereas the NN model recommends 0 to $5900 \mathrm{lb} / \mathrm{MMBTU}$ of assisted air and $\mathrm{NHV}_{\mathrm{vg} \text {, req }}$ is the same as the experimental $\mathrm{NHV}_{\mathrm{vg}}$ (339-2117 BTU/scf). Table 5 summarizes the comparison 


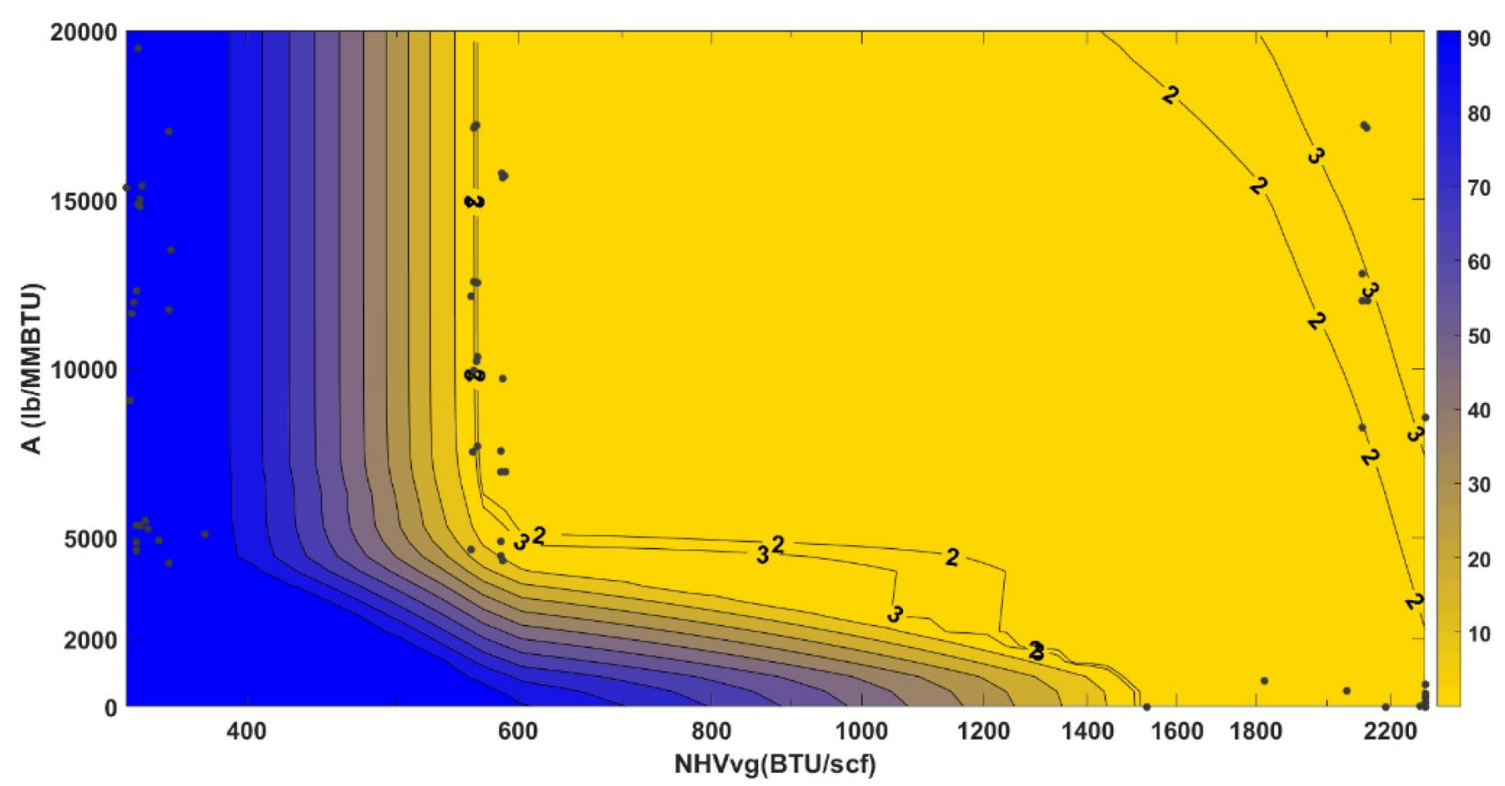

Fig. 12 2D contour plot of \% Opacity on $\mathrm{NHV}_{\mathrm{vg}}$ vs A for air-assisted flares at fixed D (1.5 ft), V (1 ft/s) and U (10 ft/s)

Fig. 13 Predicted air assist at ISP vs smokeless flaring (SLF)

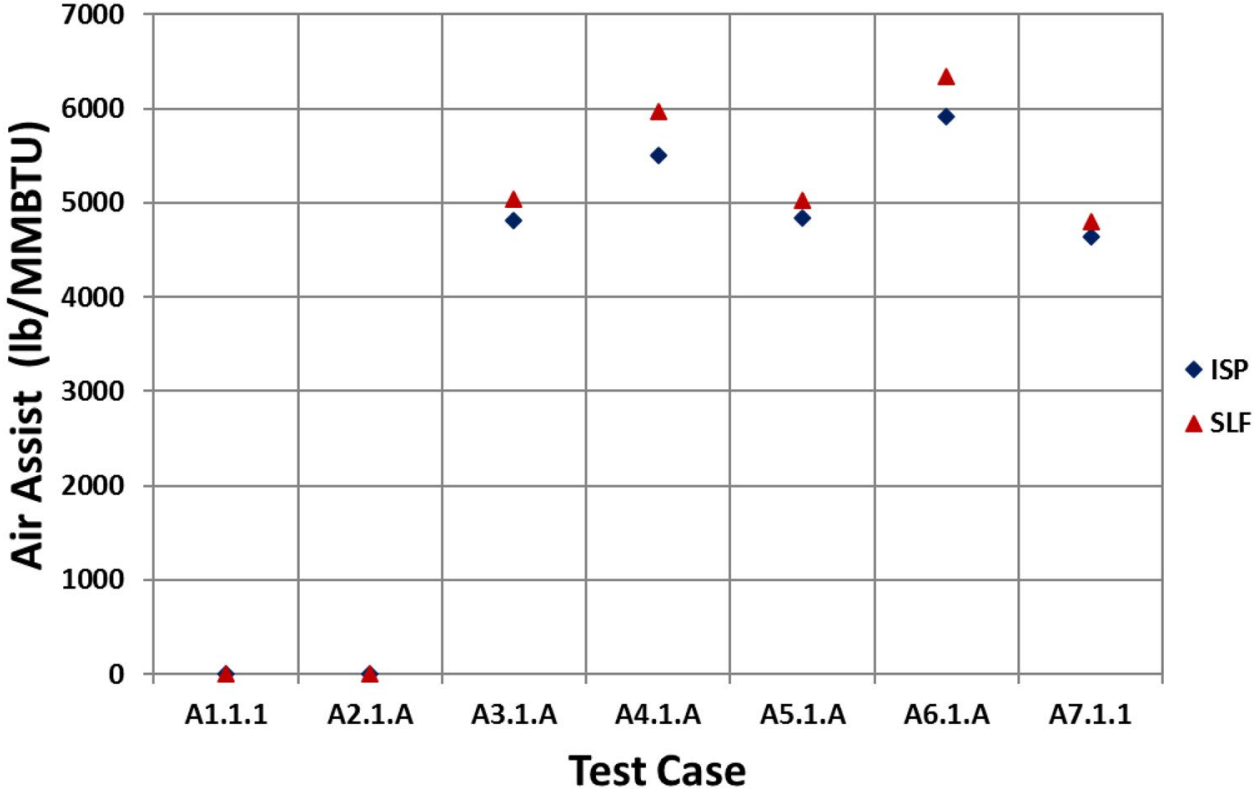

of assistance steam/air predicted by NN model against the values determined by ISP characterization by Chen et al. [28]. The formula to calculate $\mathrm{NHV}_{\mathrm{vg} \text {, req }}$ is given as follows:

$\mathrm{NHV}_{\mathrm{VG}, \text { req }}=\frac{\mathrm{NHV}_{\mathrm{VG}} \times Q_{\mathrm{VG}}+Q_{\mathrm{f}} \times N H V_{\mathrm{f}}+Q_{\mathrm{p}} \times N H V_{\mathrm{p}}}{Q_{\mathrm{VG}}+Q_{\mathrm{f}}+Q_{\mathrm{p}}}$,

where $Q_{\mathrm{VGis}}$ volume flow rate of vent gas (scf/hr), $Q_{\mathrm{p}}$ volume flow rate of pilot gas used $(\mathrm{scf} / \mathrm{hr}), Q_{\mathrm{f}}$ volume flow rate of make-up fuel used (scf/hr), $\mathrm{NHV}_{\mathrm{VG}}$, req net heating value of vent gas, required (btu/scf), $\mathrm{NHV}_{\mathrm{f}}$ net heating value of make-up fuel (btu/scf) and $\mathrm{NHV}_{\mathrm{P}}$ net heating value of pilot gas used (btu/scf).

For the steam-assisted flare tests, the setpoints at the ISP and at SLF were determined using the same methodology. Figs. 16, 17, and 18 show predicted steam assist, \% CE and $\mathrm{NHV}_{\mathrm{CZ}}$, respectively, at the ISP vs SLF. All the steam cases required no make-up fuel to meet the criteria at ISP/SLF.

While over-steaming/aeration can suppress smoke, it is usually at the expense of combustion efficiency and this has been demonstrated both by the setpoint results and the contour plots of CE and Opacity. The discrepancy 


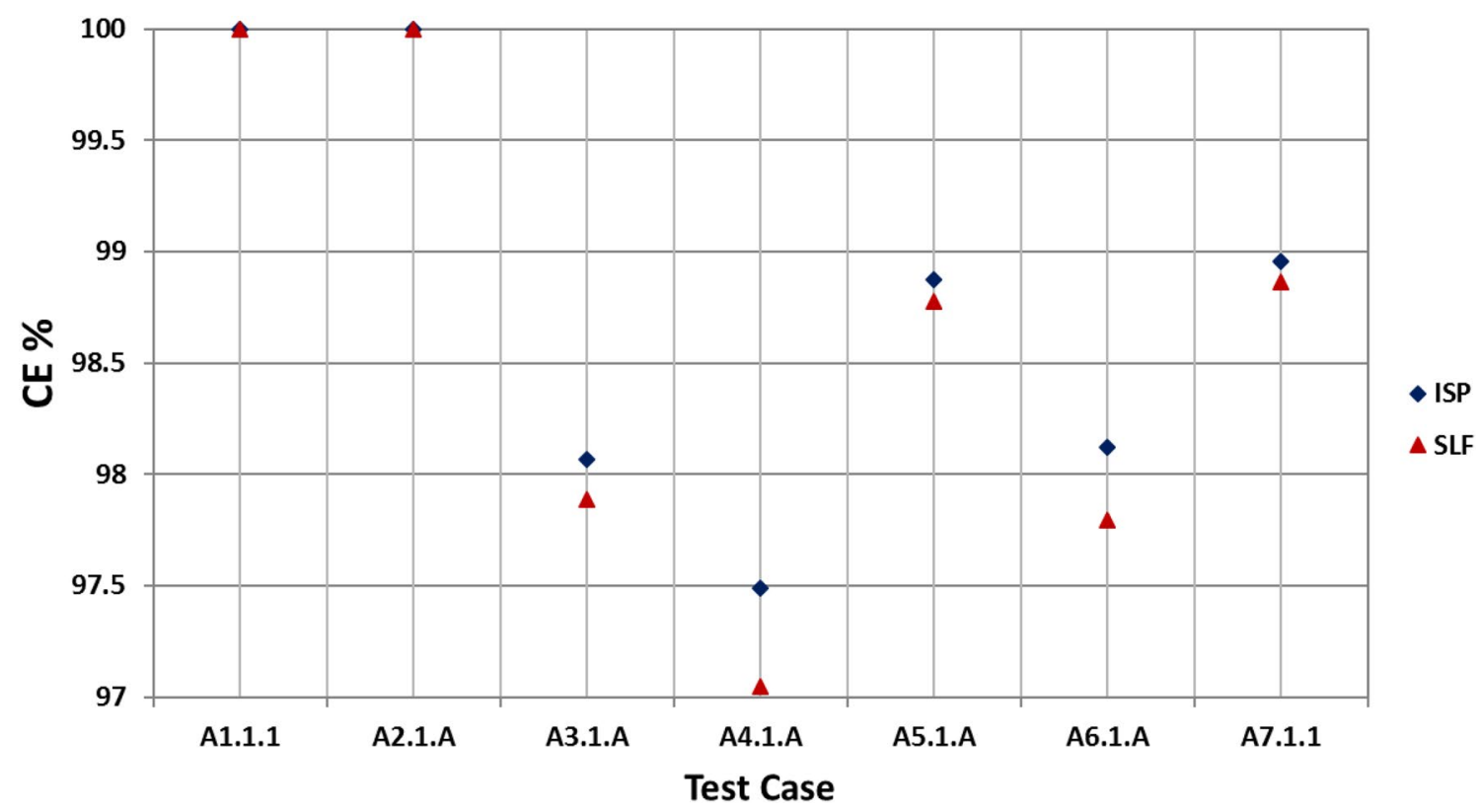

Fig. 14 Predicted CE at ISP vs smokeless flaring (SLF) for air-assisted flares

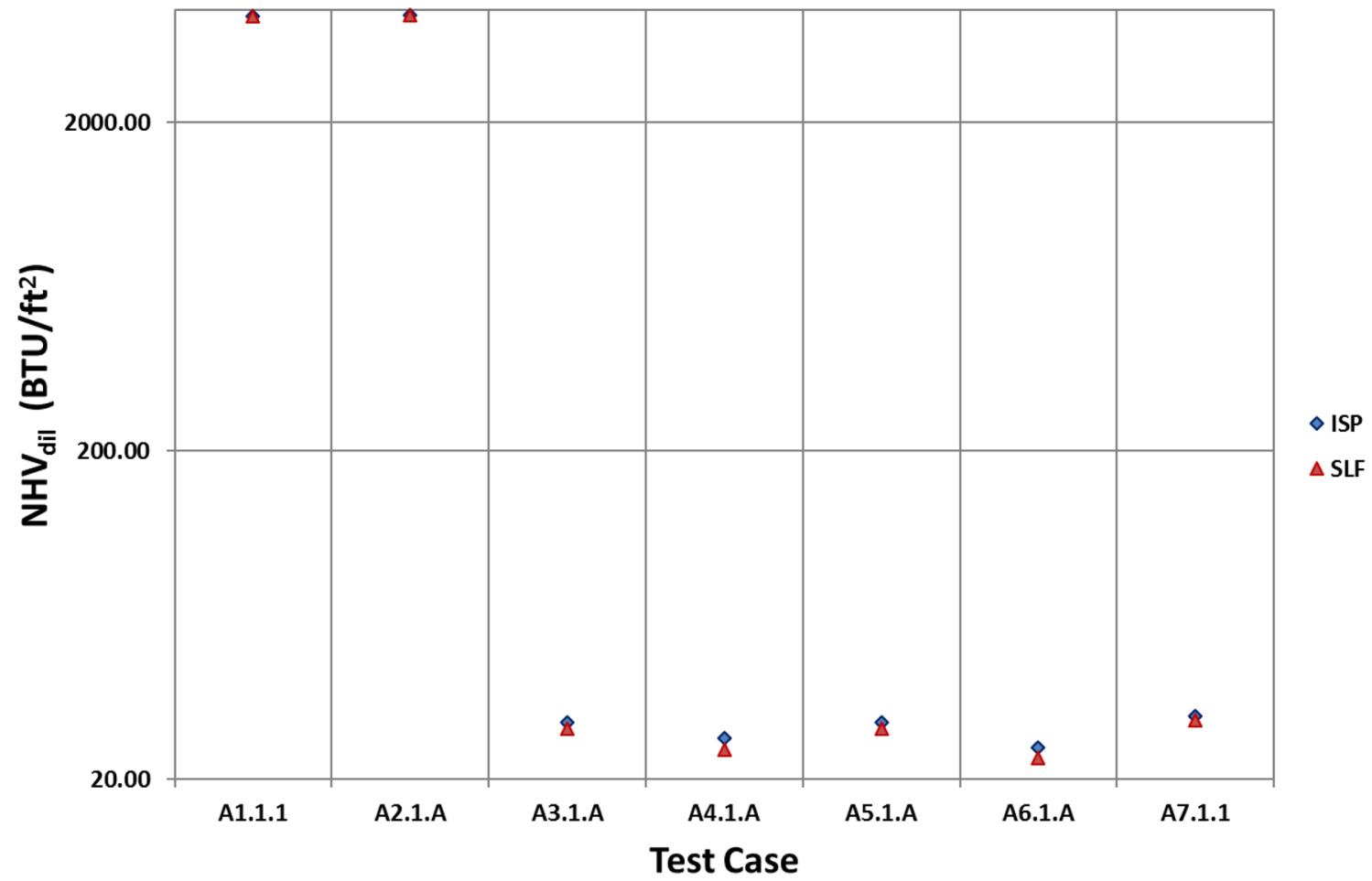

Fig. 15 Predicted $\mathrm{NHV}_{\text {dil }}$ at ISP vs smokeless flaring (SLF) for air-assisted flares

between the predicted ISP steam/air/make-up fuel and experimental data can be justified: First, the observed ISP are not very rigorous due to human observation errors as seen by the wide variations in characterized ISP opacity, combustion efficiency, heating value, etc.; Secondly, the
ISP or SLF can be achieved in multiple states by simultaneously increasing $\mathrm{NHV}_{\mathrm{vg} \text {, req }}\left(\mathrm{NHV}_{\mathrm{vg}}\right.$ and make-up fuel) and the diluent (steam and air assist) for better air mixing. Therefore, ISP or SLF can be achieved by simultaneously introducing make-up fuel and steam or by reducing steam 
Table 5 Comparison of results by ISP characterization [56] and NN models

\begin{tabular}{lll}
\hline & $\begin{array}{l}\text { Assisted steam (lb/ } \\
\text { MMBTU) }\end{array}$ & $\begin{array}{l}\text { Assisted } \\
\text { air (lb/ } \\
\text { MMBTU) }\end{array}$ \\
\hline ISP characterization & $16-211$ & $\begin{array}{l}4431-8609 \\
\text { NN models }\end{array}$ \\
\hline
\end{tabular}

(or air) alone. Even though adding no make-up fuel is the priority in the solution algorithms, it will be interesting to compare the solution of the minimization of fuel and steam/air use and maximization of combustion efficiency (CE) to the present work.

\section{Conclusion}

Artificial neural network (ANN) models that showed good correlation coefficients between experimental data (controlled flare tests from 1983 to 2014) and model predictions were developed for both steam- and air-assisted flares. The models included performance models for opacity, combustion efficiency (CE), and operation models for assistance steam and air. Input variables include $\mathrm{NHV}_{\mathrm{vg}}, \mathrm{S}, \mathrm{A}, \mathrm{NHV}_{\mathrm{CZ}}$, $\mathrm{NHV}_{\text {dil }}, \mathrm{D}, \mathrm{V}, \mathrm{U}, \mathrm{CN}$, and CHR, where carbon to hydrogen atomic ratio $(\mathrm{CHR})$ and carbon number $(\mathrm{CN})$ reflect vent gas species effect and $\mathrm{NHV}_{\mathrm{CZ}}$ and $\mathrm{NHV}_{\text {dil }}$ are parameters that combine the effect of steam/air assists and vent gas heating value $\mathrm{NHV}_{\mathrm{vg}}$ to facilitate easy flare control. NN models for

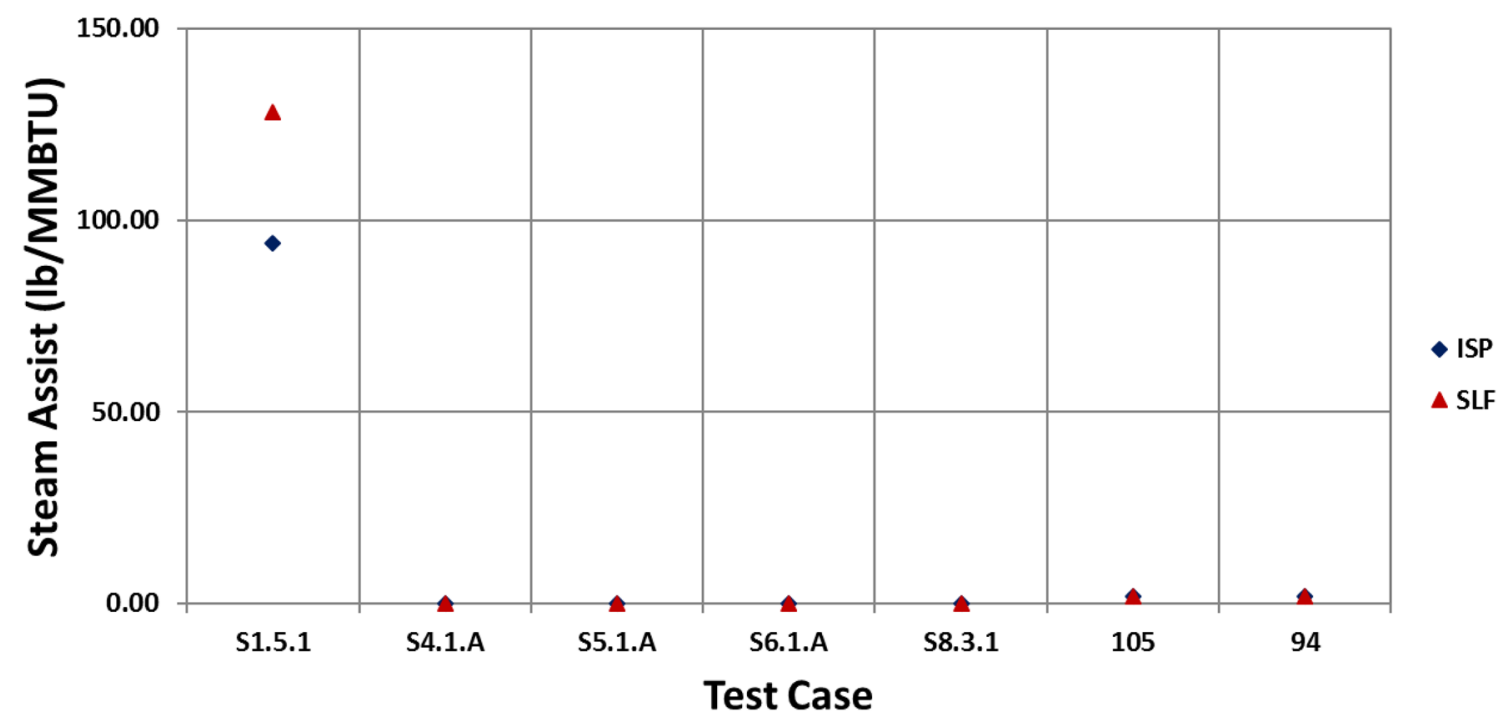

Fig. 16 Predicted steam assist at ISP vs smokeless flaring (SLF)

Fig. 17 Predicted CE at ISP vs smokeless flaring (SLF) for steam-assisted flares

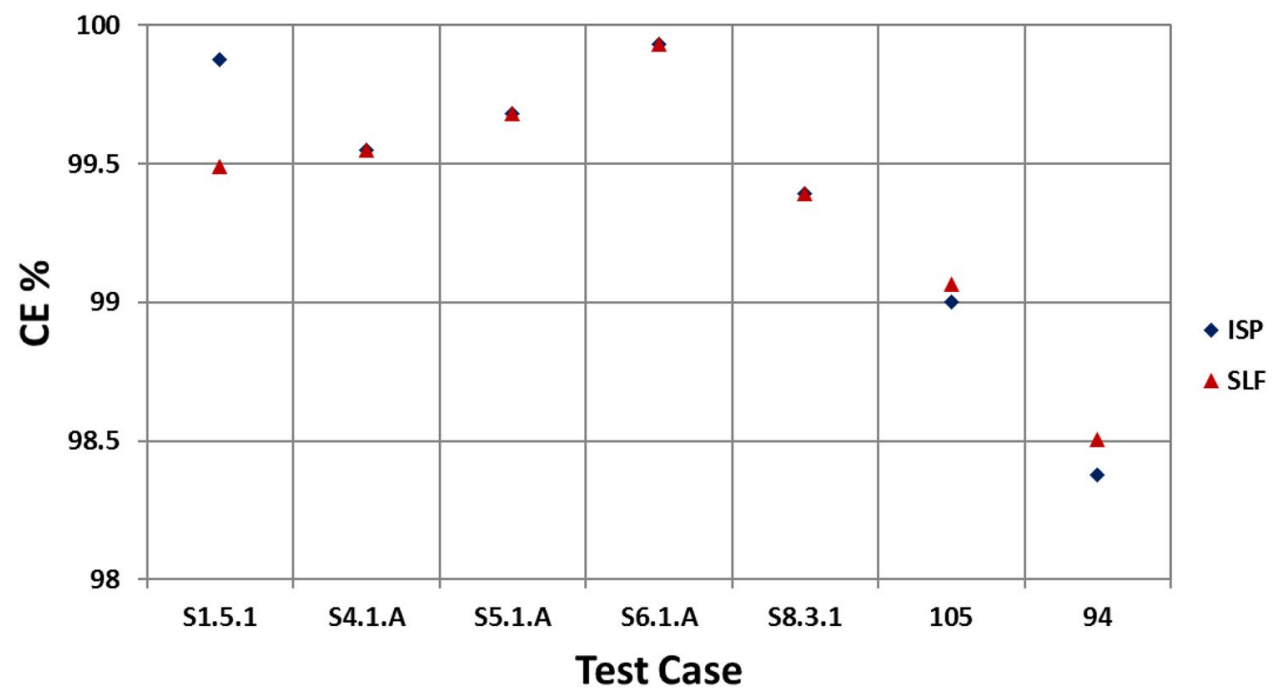


Fig. 18 Predicted $\mathrm{NHV}_{\mathrm{CZ}}$ at the ISP vs smokeless flaring (SLF) for steam-assisted flares

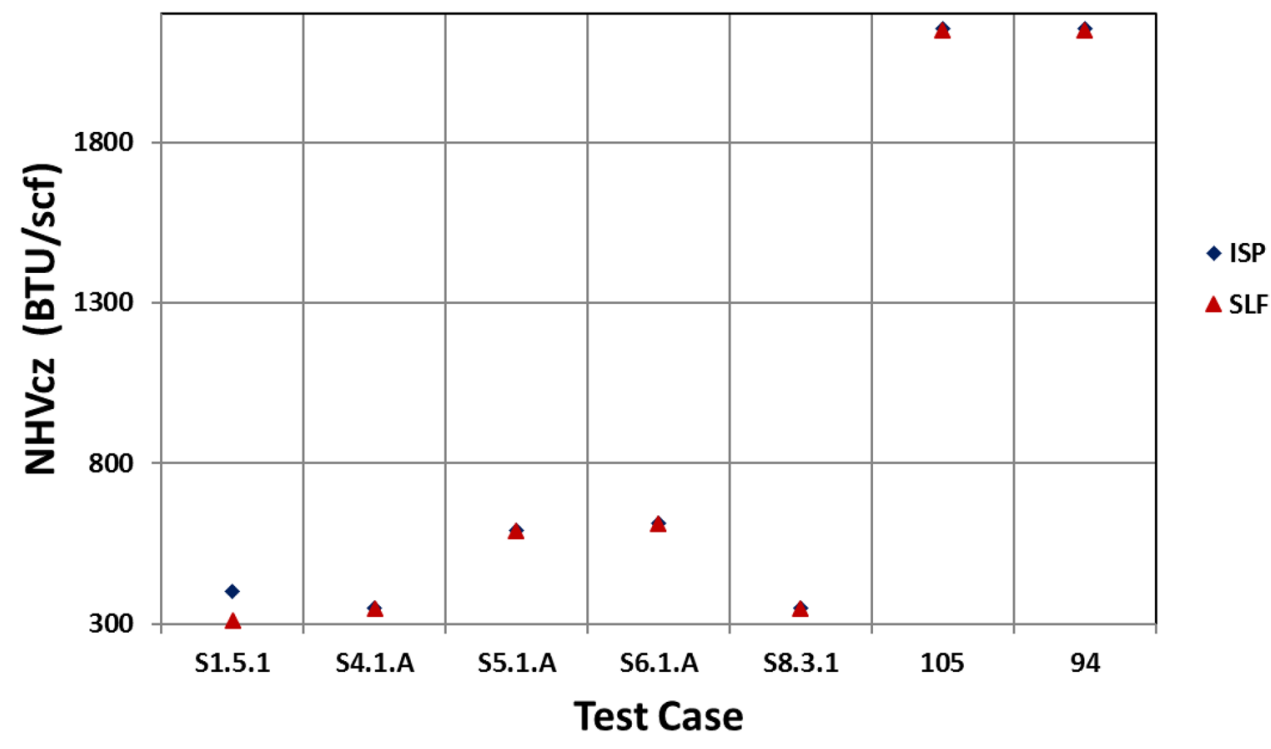

steam- and air-assisted flare tests have shown a good agreement with experimental data and this has been demonstrated by the average correlation coefficient being 0.95 and 0.97 for air-assisted and steam-assisted flare data, respectively. The mean absolute errors of $1.1 \%$ and $1.4 \%$ for air-assisted and steam-assisted flare data, respectively also confirm the performance and robustness of the $\mathrm{NN}$ models. As shown in Table 5 it can be stated that NN predictions at the ISP are in good agreement and well within the boundaries set by the ISP characterization paper. The 2-D contour plots have been presented to show the trends of the important parameters emphasizing the interaction between \% CE, \% Opacity, and assistance air/steam.

Specific set points of the controllable variables like steam/ air assist and make-up fuel were determined using ANN that satisfies stipulated $\mathrm{NHV}_{\mathrm{CZ}} \geq 270 \mathrm{BTU} / \mathrm{scf}$ (for steamassisted flares) or $\mathrm{NHV}_{\mathrm{dil}} \geq 22 \mathrm{BTU} / \mathrm{scf}$ (for air-assisted flares) and opacity $=3 \%$ for the ISP and opacity $=2 \%$ (operating slightly below ISP) for SLF. Operating slightly below the ISP opacity should be most economical. The NN models built in this study demonstrated that by reducing the amount of air/steam used smokeless flaring can be achieved for vent gases with high net heating values while still complying with $\mathrm{CE} \geq 96.5 \%$. The models built are reliable to guide flare operations in compliance with regulations.

Acknowledgements The authors acknowledge financial support from TCEQ Grant for Activities Program (Project\# 582-10-94,307-FY1406), TCEQ Supplemental Environmental Program (SEP Agreement no. 2009-009), and the Texas Air Research Center (TARC Grant\# 079LUB0096A). Special thanks are due to Ed Fortner and Scott Herndon of Aerodyne Research, Inc. (for numeric soot data from $2010 \mathrm{JZ}$ flare campaign), Dr. Darcy Corbin and Dr. Matthew Johnson (for flare study data at Carleton University, 2014), and Dr. Yousheng Zeng (for flare study data by Providence Photonics in 2014).
Open Access This article is distributed under the terms of the Creative Commons Attribution 4.0 International License (http://creativeco mmons.org/licenses/by/4.0/), which permits unrestricted use, distribution, and reproduction in any medium, provided you give appropriate credit to the original author(s) and the source, provide a link to the Creative Commons license, and indicate if changes were made.

\section{References}

1. Strosher, M.T.: Characterization of emissions from diffusion flare systems. J. Air Waste Manag. Assoc. (2000). https://doi. org/10.1080/10473289.2000.10464218

2. Marrero, J.E., Townsend-Small, A., Lyon, D.R., Tsai, T.R., Meinardi, S., Blake, D.R.: Estimating emissions of toxic hydrocarbons from natural gas production sites in the Barnett Shale Region of Northern Texas. Environ. Sci. Technol. (2016). https://doi. org/10.1021/acs.est.6b02827

3. RTI International. Emissions estimation protocol for petroleum refineries. Research Triangle Park, NC (2015). https://www3.epa. gov/ttn/chief/efpac/protocol/Protocol Report 2015.pdf

4. The World Bank.: Global gas flaring reduction partnership (GGFR). Available at: http://www.worldbank.org/en/programs/ gasflaringreduction. Accessed 17 Apr 2019

5. Bader, A., Baukal, C.E., Bussman, W.: Selecting the proper flare systems. Chem. Eng. Prog. 107(7), 45-50 (2011)

6. Ismail, O.S., Umukoro, G.E.: Modelling combustion reactions for gas flaring and its resulting emissions. J. King Saud Univ. Eng. Sci. (2016). https://doi.org/10.1016/j.jksues.2014.02.003

7. Russ Nettles, Russ Nettles, Air Quality Division.: Texas commission on environmental quality (TCEQ) 2010 flare study \& supplemental flare operations training (2014). Available at: https:// www.cleanairact.org/events/documents/NETTLES.pdf. Accessed 11 Aug 2019

8. Stohl, A., Klimont, Z., Eckhardt, S., Kupiainen, K., Shevchenko, V.P., Kopeikin, V.M., Novigatsky, A.N.: Black carbon in the Arctic: the underestimated role of gas flaring and residential combustion emissions. Atmos. Chem. Phys. (2013). https://doi. org/10.5194/acp-13-8833-2013

9. Caulton, D.R., Shepson, P.B., Santoro, R.L., Sparks, J.P., Howarth, R.W., Ingraffea, A.R., Cambaliza, M.O.L., Sweeney, C., Karion, 
A., Davis, K.J., Stirm, B.H., Montzka, S.A., Miller, B.R.: Toward a better understanding and quantification of methane emissions from shale gas development. Proc. Natl. Acad. Sci. (2014). https ://doi.org/10.1073/pnas.1316546111

10. Schneising, O., Burrows, J.P., Dickerson, R.R., Buchwitz, M., Reuter, M., Bovensmann, H.: Remote sensing of fugitive methane emissions from oil and gas production in North American tight geologic formations. Earth's Future (2014). https://doi. org/10.1002/2014ef000265

11. Farina, M.F.: Flare gas reduction: recent global trends and policy considerations. General Electric Company (2011)

12. Weyant, C.L., Shepson, P.B., Subramanian, R., Cambaliza, M.O.L., Heimburger, A., McCabe, D., Baum, E., Stirm, B.H., Bond, T.C.: Black carbon emissions from associated natural gas flaring. Environ. Sci. Technol. (2016). https://doi.org/10.1021/acs. est.5b04712

13. Gvakharia, A., Kort, E.A., Brandt, A., Peischl, J., Ryerson, T.B., Schwarz, J.P., Smith, M.L., Sweeney, C.: Methane, black carbon, and ethane emissions from natural gas flares in the Bakken Shale, North Dakota. Environ. Sci. Technol. (2017). https://doi. org/10.1021/acs.est.6b05183

14. Elvidge, C.D., Zhizhin, M., Baugh, K., Hsu, F.C., Ghosh, T.: Methods for global survey of natural gas flaring from visible infrared imaging radiometer suite data. Energies (2016). https:// doi.org/10.3390/en9010014

15. Elvidge, C.D., Bazilian, M.D., Zhizhin, M., Ghosh, T., Baugh, K., Hsu, F.C.: The potential role of natural gas flaring in meeting greenhouse gas mitigation targets. Energy Strateg. Rev. (2018). https://doi.org/10.1016/j.esr.2017.12.012

16. Office of the Federal Register, N.A. and R.A. 83 FR 15458: National emission standards for hazardous air pollutants and new source performance standards: petroleum refinery sector amendments. Federal Register 83(69) (2018). Available at: https://www. govinfo.gov/app/details/FR-2018-04-10/2018-06223. Accessed 11 Aug 2019

17. US Environmental Protection Agency.: Parameters for properly designed and operated flares (2012)

18. U.S. EPA.: Review \& peer review of "Parameters for properly designed and operated flares" documents. Available at: https:// www.epa.gov/stationary-sources-air-pollution/review-peer-revie w-parameters-properly-designed-and-operated-flares. Accessed 11th Aug 2019

19. Baukal, C.E., Schwartz, R.E.: The John zink Combustion Handbook. CRC Press, Boca Raton (2001). (ISBN 0-8493-2337-1)

20. Walls, S., Knauf, M.: NSPS Subpart Ja flare management planplan elements and lessons learned. in: american fuel and petrochemical manufacturers. In: AFPM-Environmental Conference 2014: Enforcement Initiatives (2014)

21. EPA: Enforcement targets flaring efficiency violations. Enforcement Alert, 10(5). EPA 325-F-012-002 (2012)

22. U.S. EPA.: Petroleum refinery sector risk and technology review and new source performance standards. Fed. Register 80, 7517875229 (2015)

23. Zeng, Y., Morris, J., Dombrowski, M.: Validation of a new method for measuring and continuously monitoring the efficiency of industrial flares. J. Air Waste Manag. Assoc. (2016). https://doi. org/10.1080/10962247.2015.1114045

24. U.S. EPA.: 40 CFR Part 60: oil and natural gas sector: emission standards for new, reconstructed, and modified sources. 81(107) (2016).https://www.govinfo.gov/content/pkg/FR-2016-06-03/ pdf/2016-11971.pdf

25. Holden, J.: MACT rule will have effect on stationary engines. Pipeline Gas J. 232(10), 31-33 (2005)

26. US Environmental Protection Agency.: Oil and natural gas sector: new source performance standards and national emission standards for hazardous air pollutants reviews Final rule. Fed. Regist. 77(159), 49-490 (2012)

27. Alphones, A., Damodara, V., Chen, D.H., Fortner, E.C., Evans, S., Johnson, M.R.: Response surface modeling of flare performance and characterization of the incipient smoke point. In 2015 AIChE annual meeting. Paper no. 199e (2015)

28. Chen, D.H., Alphones, A.: Characterization of the incipient smoke point for steam-/air-assisted and nonassisted flares. J. Air Waste Manag. Assoc 69(1), 119-130 (2019)

29. Singh, K.D., Gangadharan, P., Dabade, T., Shinde, V., Chen, D., Lou, H.H., Richmond, P.C., Li, X.: Parametric study of ethylene flare operations using numerical simulation. Eng. Appl. Comput. Fluid Mech. (2014)

30. Allen, D.T., Torres, V.M.: Texas commission on environmental quality TCEQ 2010 flare study final report (2011). Available at: https://www.tceq.texas.gov/assets/public/implementation/air/rules /Flare/2010flarestudy/2010-flare-study-final-report.pdf. Accessed 11 Aug 2019

31. Clean Air Engineering, I.: Performance test of a steam-assisted elevated flare with passive FTIR-detroit final report. Marathon Petroleum Company, LP Detroit Refinery. (2010)

32. Marathon Petroleum Company, L.: Performance test of a steamassisted elevated flare with passive FTIR., Texas City, Texas (2010)

33. Providence Engineering.: Technology I Flare combustion efficiency monitoring I Providence engineering. Available at: http:// www.providenceeng.com/projects/category/technology/flare -combustion-efficiency-monitoring. Accessed 27 Oct 2018

34. Corbin, D.J., Johnson, M.R.: Summary of flare efficiency and soot emission rate measurement results at Carleton University Energy \& Emissions Research Lab: Final Report; TCEQ Project number 582-10-94307-FY14-06; Prepared for TCEQ., Ottawa, ON, Canada (2014)

35. McEwen, J.D.N., Johnson, M.R.: Black carbon particulate matter emission factors for buoyancy-driven associated gas flares. J. Air Waste Manag. Assoc. (2012). https://doi.org/10.1080/10473 289.2011.650040

36. McDaniel, M., Tichenor, B.A.: Flare efficiency study (1983)

37. Aerodyne Research Mobile Laboratory.: Particulate measurements, TCEQ 2010 flare study. Available at: https://www.tceq. texas.gov/assets/public/implementation/air/rules/Flare/2010flares tudy/2010-flare-study-final-appendices-particulates.pdf. Accessed 11 Aug 2019

38. Pohl, J.H., Lee, J., Payne, R., Tichenor, B.A.: Combustion efficiency of flares. Combust. Sci. Technol. (1986). https://doi. org/10.1080/00102208608923934

39. Damodara, V., Chen, D.H., Lou, H.H., Rasel, K.M.A., Richmond, P., Wang, A., Li, X.: Reduced combustion mechanism for C1-C4 hydrocarbons and its application in computational fluid dynamics flare modeling. J. Air Waste Manag. Assoc. (2017). https://doi. org/10.1080/10962247.2016.1268546

40. Singh, K.D., Gangadharan, P., Chen, D.H., Lou, H.H., Li, X., Richmond, P.: Computational fluid dynamics modeling of laboratory flames and an industrial flare. J. Air Waste Manag. Assoc. (2014). https://doi.org/10.1080/10962247.2014.948229

41. Singh, K.D., Dabade, T., Vaid, H., Gangadharan, P., Chen, D., Lou, H.H., Li, X., Li, K., Martin, C.B.: Computational fluid dynamics modeling of industrial flares operated in stand-by mode. Ind. Eng. Chem. Res. (2012). https://doi.org/10.1021/ie300639f

42. MATLAB.: Multilayer neural network using backpropagation algorithm (2015)

43. Madsen, K., Nielsen, H.B., Tingleff, O.: Methods for non-linear least square problems. Soc. Ind. Appl, Math (2004)

44. Prechelt, L.: Early stopping - but when? Lect. Notes Comput. Sci. (2012). https://doi.org/10.1007/978-3-642-35289-8-5 
45. Leven, S.: The roots of backpropagation: from ordered derivatives to neural networks and political forecasting: By Paul J. Werbos. New York: John Wiley. \$54.95, 319 pages, ISBN 0-471-59897-6, pp. 543-544 (1996)

46. Rumelhart, D.E., Durbin, R., Golden, R., Chauvin, Y.: Backpropagation: the basic theory. In: Chauvin, Y., Rumelhart, D.E. (eds.) Developments in connectionist theory. Backpropagation: theory, architectures, and applications, pp. 1-34. Lawrence Erlbaum Associates Inc, Hillsdale, NJ, US (1995)

47. Rumelhart, D.E., Hinton, G.E., Williams, R.J.: Learning representations by back-propagating errors. Nature (1986). https://doi. org $/ 10.1038 / 323533 \mathrm{a} 0$

48. Hagan, M.T., Menhaj, M.B.: Training feedforward networks with the Marquardt algorithm. IEEE Trans. Neural Netw. (1994). https ://doi.org/10.1109/72.329697

49. Rojas, R.: Neural networks: a systematic introduction. Neural Netw. (1996). https://doi.org/10.1016/0893-6080(94)90051-5

50. Arbib, M., Ballard, D., Bower, J., Orban, G.: Neural networks algorithms, applications. Neural Net 7, 209-212 (1994)

51. Gershenson, C.: Artificial neural networks for beginners. Networks (2003). https://doi.org/10.1093/icesjms/fsp009

52. Vega-Carrillo, H.R., Martín Hernández-Dávila, V., ManzanaresAcuña, E., Sánchez, G.A.M., De La Torre, M.P.I., Barquero, R., Palacios, F., Villafañe, R.M., Arteaga, T.A., Rodriguez, J.M.O.: Neutron spectrometry using artificial neural networks. Radiat. Meas. (2006). https://doi.org/10.1016/j.radmeas.2005.10.003

53. Wang, H.N., Cui, Y.M., Li, R., Zhang, L.Y., Han, H.: Solar flare forecasting model supported with artificial neural network techniques. Adv. Sp. Res. (2008). https://doi.org/10.1016/j. asr.2007.06.070

54. Kahforoshan, D., Fatehifar, E., Babalou, A.A., Ebrahimin, A.R., Elkamel, A., Soltanmohammadzadeh, J.S.: Modeling and evaluation of air pollution from a gaseous flare in an oil and gas processing area. In: WSEAS conferences in Santander (2008)

55. Bellasio, R. (2012) Enviroware srl. Modelling industrial flares impacts (2012). Available at: https://www.enviroware.com/model ling-industrial-flares-impacts/ModellingIndustrialFlaresImpac ts.pdf. Accessed 11 Aug 2019

56. Willis, J.: Flare efficiency estimator and case studies. Water Intell. Online (2015). https://doi.org/10.2166/9781780404882

57. Tamas, W.W., Notton, G., Paoli, C., Voyant, C., Nivet, M.L., Balu, A.: Urban ozone concentration forecasting with artificial neural network in \{Corsica\}. arXiv1306.0897 [cs]. (2013)

58. L. Ou, H.C.: Updated vented, flaring, and fugitive greenhouse gas emissions for crude oil production in the GREET1_2018 model. Argonne Natl. Lab. Argonne, IL, 1-9. (2014)

59. Hsu, K., Gupta, H.V., Sorooshian, S.: Artificial neural network modeling of the rainfall-runoff process. Water Resour. Res. (1995). https://doi.org/10.1029/95wr01955

60. Benardos, P.G., Vosniakos, G.C.: Optimizing feedforward artificial neural network architecture. Eng. Appl. Artif. Intell. (2007). https://doi.org/10.1016/j.engappai.2006.06.005

61. Hagan, M.T., Demuth, H.B.: Neural networks for control. Am. Control Conf. 15, 20 (1999). https://doi.org/10.1109/ acc.1999.786109

Publisher's Note Springer Nature remains neutral with regard to jurisdictional claims in published maps and institutional affiliations. 